Continental Shelf Research

February 2017, Volume 134, Pages 39-51

http://dx.doi.org/10.1016/i.csr.2017.01.003

http://archimer.ifremer.fr/doc/00366/47688/

(C) 2017 Elsevier Ltd. All rights reserved.

\title{
Acoustic backscatter by suspended cohesive sediments: field observations, Seine Estuary, France
}

\author{
Sahin Cihan ${ }^{1,{ }^{*}}$, Verney Romaric ${ }^{2}$, Sheremet Alexandru ${ }^{3}$, Voulgaris George ${ }^{4}$
}

${ }^{1}$ Department of Civil Engineering, Yildiz Technical University, Esenler, Istanbul 34210, Turkey

2 IFREMER, Hydrodynamics and Sediment Dynamics Laboratory (DYNECO/PHYSED), BP 70, 29280

Plouzan, France

${ }^{3}$ Department of Civil and Coastal Engineering, University of Florida, 365 Weil Hall, P.O. Box 116590,

Gainesville, FL 32611, USA

${ }^{4}$ School of the Earth, Ocean and Environment, University of South Carolina, Columbia, SC 29208, USA

*Corresponding author : Cihan Sahin, email addresses : cisahin@inm.yildiz.edu.tr ; cisahin@ufl.edu

\begin{abstract}
:
Observations of suspended sediment size and concentration, flow and acoustic backscatter intensity collected on the Seine Estuary (France) are used to study the acoustic response in cohesive-sediment dominated environments. Estimates of suspended sediment concentration based on optical backscatter sensors and water samples are used to calibrate the acoustic backscatter intensity. The vertical structure of suspended sediment concentration is then estimated from acoustic backscatter information. To our knowledge, this is the first field application of the recently proposed model of acoustic scattering by flocculating suspensions based on the variation of particle density (floc-scattering model). The estimates of sediment concentration reproduce well the observations under different tidal (neap/spring) conditions, confirming the applicability of the new model in the field when detailed particle size measurements are available. When particle size measurements are not available, using estimated floc sizes based on the turbulence intensities may provide reasonable SSC profiles. During spring tide events (associated with strong currents, small flocs and large concentrations), the performances of the new floc-scattering model and the previous models given for solid particle-scattering are comparable. The floc-scattering model increases the quality of the SSC estimates especially during low-energy conditions characterized with larger flocs.
\end{abstract}

\section{Highlights}

- This is the first field application of the recently proposed model of acoustic scattering by flocculating suspensions. The applicability of the new model in the field is confirmed when detailed particle size measurements are available. When particle size measurements are not available, using estimated floc sizes based on the turbulence intensities may provide reasonable SSC profiles. The flocscattering model increases the quality of the SSC estimates especially during low-energy conditions characterized with larger flocs. 


\section{Introduction}

Suspended sediment concentration (SSC) information is essential for understanding sediment transport dynamics in estuarine and coastal environments. Acoustic profiling devices are widely used to measure both current velocity and SSC profiles since, unlike the point measurements by optical systems, they can provide information about the vertical structure of SSC. In sandy environments, where backscattering occurs from individual particles, acoustic techniques have been used intensively to estimate the vertical distribution of suspended sediment concentration and size from the backscattered signal (acoustic inversion)(e.g., Urick, 1948; Sheng and Hay, 1988; Downing et al., 1995; Crawford and Hay, 1993; Thorne and Hanes, 2002). Transferring these techniques to cohesive sediment environments such as estuaries is challenging, because cohesive sediment characteristics (size, shape, density, etc.) and flocculation are highly sensitive to flow conditions (e.g., Dyer and Manning, 1999; McAnally and Mehta, 2000; Winterwerp, 2002; Voulgaris and Meyers, 2004; Verney et al., 2011; Safak et al., 2013; Wang et al., 2013; Sahin, 2014). As a consequence, the use of acoustic backscatter systems to study sediment transport processes in fine-grained, cohesive environments is generally considered less accurate. All of the few studies published so far (e.g., Gartner, 2004; Hoitink and Hoekstra, 2005; Ha et al., 2011; Sahin et al., 2013; Sahin, 2014) acknowledge the difficulty and uncertainty of interpretation of the acoustic observations when sediment flocculation is present.

Acoustic and optical backscatter show a distinct sensitivity to flocculation. Vincent and MacDonald (2015) showed that there are small but systematic decreases in the optical backscattered signal between the primary and flocculated particles typically between $9 \%$ and $20 \%$ depending on the concentration. This small change in backscattered signal suggests that the size of particles scattering the light (sub-particles constituting the flocs) may increase a little as the degree of flocculation increases, given that the optical backscatter is inversely proportional to the particle diameter for a given mass concentration (Fugate and Friedrichs, 2002; Ha et al., 2009). They conclude that the changes in the optical backscatter that occur between primary (unflocculated) and flocculated particles are relatively small, from the point of view of a marine scientist wishing to measure concentrations of fine sediment. Accordingly, optical instruments are commonly used to measure sediment concentration in environments dominated with flocculated particles (e.g., Kineke and Sternberg, 1992; Safak et al., 2013; Sahin et al., 2013; Verney et al., 2013; Sahin, 2014). In contrast, acoustic backscatter intensity increases with the growth of particle (or floc). Although the signal intensity increases as the floc size increases, the intensity is much smaller for flocs than that for the solid particles of same size 
(MacDonald et al., 2013; Vincent and MacDonald, 2015). In previous studies, acoustic backscatter sensitivity to flocculation was related to low density of the aggregates and their porous nature (Ha et al., 2009, 2011; MacDonald et al., 2013; Rouhnia et al., 2014). In ADV-based (ADV: Acoustic Doppler Velocimeter) measurements of floc growth, Rouhnia et al. (2014) observed that the backscattered signal intensity increases rapidly with floc size up to certain value, then the rate of increase significantly slows down for larger flocs.

The analysis of acoustic backscatter data from muddy environments is hampered by the fact that the main features of scatterers are essentially unknown. It is still unclear in which form (i.e., primary particles, microflocs or macroflocs) the cohesive sediment should be considered as scatterers. Most of the previous studies suggest that scattering characteristics of a suspension of flocculated particles are controlled by the floc properties, rather than constituent primary particles. Theoretically, the marginal value of $k a$ (where $k$ is the wave number of the acoustic signal and $a$ is the mean radius of scattering particle in suspension) for detection of suspended sediment particles may be roughly about 0.05 , suggesting that acoustical devices operating at MHz frequencies would not be capable to resolve SSC well for grain sizes of order of $1 \mu \mathrm{m}$, a typical primary particle size constituting flocs in muddy environments (Lynch et al., 1994; Ha et al., 2011). Gartner (2004) successfully estimated concentration profiles by using flocs as scatterers with $1,200-\mathrm{kHz}$ and 2,400-kHz acoustic Doppler current profilers (ADCP). Ha et al. (2011), using a 1,500-kHz pulse-coherent acoustic Doppler profiler (PC-ADP), suggested that the acoustic signal responds to compacted and robust flocs as a whole, rather than to the primary constituent particles. With a $1,500-\mathrm{kHz}$ PC-ADP, inversion calculations by Sahin et al. (2013) using alternatively flocs and primary particles as scatterers consistently showed a better agreement for flocs, with a marginally significant correction due to primary-particle viscous effect. In contrast, a study by Fugate and Friedrichs (2002) suggests that the acoustic signal may penetrate the pores of flocs, and therefore the acoustic response for resuspended aggregates depends mostly on the constituent grains rather than the floc characteristics. Vincent and MacDonald (2015) recently speculated that the acoustic signal is sensitive to the sub-particles within the larger particles (flocs), referred to as flocculi, and that the flocculi could be treated as elastic spheres with density and acoustic wave propagation speeds equal to primary particles. However, the lack of field measurements of SSC and floc size with high spatial and temporal resolution may have precluded previous efforts from drawing a clear conclusion. A careful examination evaluating both views is warranted.

In the absence of a theoretical framework to describe the interactions between flocculated sediments and 
sound, previous applications involving possible scattering by mud flocs have defaulted to using expressions derived for solid (primary-particle) scatterers. Recently, MacDonald et al. (2013) carried out the first experimental study to investigate the interaction of sound with a suspension of flocculated sediments under controlled conditions, i.e., in a homogeneous suspension with known primary and flocculated sediment size and concentrations. Their results show significant differences between sediment backscattering properties before, and after aggregation, suggesting that the scattering characteristics are not solely controlled by the primary particles, but are also influenced by the presence of the flocs. The order-of-magnitude difference between the values of scattering parameters (e.g., form function, total scattering cross-section) obtained for flocs and for quartz primary particles is significant and casts doubt on the applicability of expressions previously derived for solid scatterers in applications involving flocculated particles. In a complementary study, Thorne et al. (2014) proposed the first model for the modification of scattering characteristics as the sediment flocculates, transitioning from separate primary particles to large low-density aggregates. The approach models primary particles as solid elastic spheres, and large, low-density flocs as fluid elastic spheres. This leads to a new model, so-called a hybrid model, that uses a variable particle density to represent the processes of flocculation. The model captures well the general behavior observed by MacDonald et al. (2013).

Here, we investigate the backscattering of the acoustic signal in a cohesive sediment environment under different hydrodynamic conditions. The field observations used here include optical and acoustic backscatter, as well as floc-size measurements throughout the water column, providing a detailed synchronous picture of floc variability, hydrodynamic conditions, and acoustic backscatter characteristics. This study aims to test the acoustic backscatter model for flocculates of Thorne et al. (2014) and its applicability under field conditions. We invert acoustic backscatter data in an estuarine environment to derive profiles of sediment concentration. The implications of the results are discussed in relation to importance of floc size measurements and improvements made by the new model over the previous solid-scatterer based models. 


\section{Method}

\subsection{Acoustic inversion}

The backscatter intensity of an acoustic profiler can be converted to the vertical distribution of suspended concentration, $M$, using (see Appendix)

$$
M(r)=\left\{\frac{10^{I_{d B} / 20} r \psi}{k_{s} k_{t}^{\prime \prime}}\right\}^{2} e^{4 r \alpha}
$$

with

$$
k_{t}^{\prime \prime}=\left\{\frac{3 \tau c}{16}\right\}^{1 / 2} \frac{0.96}{k a_{t}} \frac{p_{0}}{p_{\text {ref }}}, \quad k_{s}(r)=\frac{\left\langle f_{f}(r)\right\rangle}{\sqrt{\langle a(r)\rangle \rho(a)}},
$$

where $M$ is the mass concentration of suspended scatterers $\left(\mathrm{kg} \mathrm{m}^{-3}\right), r$ is the range from the transceiver along the acoustic beam $(\mathrm{m}), \psi$ is the dimensionless near-field correction factor describing the departure from spherical spreading in the near-field of the transducer, $k_{s}$ embodies the scattering properties of sediment $\left(\mathrm{kg}^{-1 / 2} \mathrm{~m}\right), k_{t}^{\prime \prime}$ is a system constant $\left(\mathrm{V} \mathrm{m}^{3 / 2}\right), \alpha$ denotes the attenuation coefficient $\left(\right.$ Nepers $\left.\mathrm{m}^{-1}\right), f_{f}$ is a form function describing the backscattering characteristics of a particle relative to its geometrical size (dimensionless), $a$ is the radius of sediment in suspension $(\mathrm{m})$, and $\rho(a)$ denotes sediment density $(\mathrm{kg}$ $\mathrm{m}^{-3}$ ). The dependency of scatterer density on particles size is used to introduce the process of flocculation into the suspension scattering characteristics. The angular brackets indicate an average over the particle number size distribution (mean value) present in the sample volume. In the expression for $k_{t}, p_{0}$ is the pressure at the reference distance $r_{0}$, which is normally defined as $1 \mathrm{~m}$; the parameter $\tau$ is the acoustic pulse duration, $c$ is the speed of sound in water, $k$ is the acoustic wave number and $a_{t}$ is the radius of the active area of the transducer. The range dependence of the parameters is not shown in the subsequent equations for simplicity.

The commercial instruments used in this study (ADCP) only provide access to the processed output signal in the manufacturer specified unit (counts) of received signal strength indicator. This is not a physical unit, but rather a relative measure of intensity for which the reference pressure is $1 \mu \mathrm{Pa}$ at $1 \mathrm{~m}$. If the ambient noise intensity, $E_{r}$, is known, then the received signal intensity, $E$, can be converted to signal intensity $I_{d B}$ (in decibels) using the expression of Gostiaux and van Haren (2010), who corrected the initially suggested formula of Deines (1999): 


$$
I_{d B}=10 \log _{10}\left(10^{K_{c} E / 10}-10^{K_{c} E_{r} / 10}\right)
$$

where $K_{c}$ is the count to decibel conversion factor $\left(\mathrm{dB}\right.$ count $\left.{ }^{-1}\right)$ which ranges from 0.4 to $0.5 \mathrm{~dB}$ count ${ }^{-1}$. The value of $K_{c}$ can be estimated through a calibration process in the laboratory or in the field using an empirical approach (e.g., Kim et al., 2004).

The attenuation coefficient $\alpha=\alpha_{w}+\alpha_{s}$ has a water component $\alpha_{w}$ and a sediment component $\alpha_{s}$. The water component of the attenuation $\alpha_{w}$ is a function of acoustic frequency, water temperature, pressure, and salinity, that may be estimated using explicit expressions or tabulated values (e.g., Francois and Garrison, 1982a, b; Kaye and Laby, 1986). The sediment attenuation term $\alpha_{s}$ can be calculated as

$$
\alpha_{s}(r)=\frac{1}{r} \int_{0}^{r} \xi(r) M(r) d r
$$

with

$$
\xi(r)=\frac{3\langle\chi(r)\rangle}{4\langle a(r)\rangle \rho(a)},
$$

where $\xi$ is the sediment attenuation constant $\left(\mathrm{kg}^{-1} \mathrm{~m}^{2}\right)$, and $\chi$ is the normalized total scattering crosssection for the particles in suspension (dimensionless). The latter quantifies the scattering from a particle over all angles relative to its cross-sectional area. It also includes the effects of viscous attenuation (Thorne et al., 2014). The parameter $\chi$ consists of two components so that $\chi=\chi_{s}+\chi_{v}$. The term $\chi_{s}$ represents the contribution to attenuation due to scattering particles, and dominates attenuation effects for large particles. The term $\chi_{v}$ accounts for frictional losses due to the viscosity of the fluid surrounding the particles for $k a \ll 1$ (Urick, 1948). Particle size affects strongly the relative importance of sediment attenuation components, and eventually the SSC calculations (Eq. 20).

In their primary unflocculated state, the particles are considered as solid elastic spheres (Eqs. 3c, 4a and 4b in Thorne et al., 2014). The model of Thorne et al. (2014) uses a modified fluid elastic sphere to characterize the scattering of large flocs with densities much closer to the density of water than that of primary particles. The intrinsic backscatter form function for an irregularly shaped fluid elastic scatterer is given as

$$
f_{f}=\frac{k_{f f} x^{2}}{1+\varepsilon_{1} x^{2}}
$$


For an irregularly shaped fluid elastic scatterer, the total normalized scattering cross-section is calculated as

$$
\chi_{s}=\frac{k_{f \alpha} x^{4}}{1-\varepsilon_{2} x+\varepsilon_{3} x^{2}+k_{f \alpha} x^{4}},
$$

where $x=k a$. The values of the dimensionless fluid heuristic formulation coefficients $\varepsilon_{1}, \varepsilon_{2}$ and $\varepsilon_{3}$ may depend on floc structure and the degree of variability in the coefficients should be realized with experimental studies. Here we used the values $\varepsilon_{1}=1.4, \varepsilon_{2}=1.5$ and $\varepsilon_{3}=1.0$ suggested by Thorne et al. (2014). Expressions for $k_{f f}$ and $k_{f \alpha}$ are

$$
k_{f f}=2\left(\frac{\gamma \zeta^{2}-1}{3 \gamma \zeta^{2}}+\frac{\gamma-1}{2 \gamma+1}\right), \quad k_{f \alpha}=2\left(\left(\frac{\gamma \zeta^{2}-1}{3 \gamma \zeta^{2}}\right)^{2}+\frac{1}{3}\left(\frac{\gamma-1}{2 \gamma+1}\right)^{2}\right)
$$

The hybrid model describes the scattering properties of the primary, transitional, and flocculated scatterers using a variable size-dependent floc density and compressional velocity of sound in the scatterer. The parameter $\gamma$ is the ratio of the density of the scatterer to the density of water, and $\zeta$ denotes the sound velocity ratio in the scatterer to that in the fluid. The velocity of sound within the flocs has not been measured and is not known. Here, we set this parameter to $\zeta=1.05$ (Thorne et al., 2014). The density of mud flocs, an indicator of the degree of flocculation, can be estimated as follows (Kranenburg, 1994)

$$
\rho(a)=\rho_{w}+\left(\rho_{s}-\rho_{w}\right)\left[\frac{D_{p}}{D_{f}}\right]^{3-n_{f}}
$$

where $\rho(a), \rho_{w}$ and $\rho_{s}$ are the densities of mud flocs, water and primary sediment particles, and $D_{f}$ and $D_{p}$ are floc and primary particle diameters, respectively. The exponent is a function of the fractal dimension $n_{f}$ of the floc, which varies between 1 and 3.

For large low-density flocs, the model prescribes the values of the parameters $f_{f}$ and $\chi$ about two orders of magnitude smaller than that of the solid particles of same size, and approach those for solid particles as the floc size decreases (or the floc density increases, Fig. 1).

\subsection{System calibration}

The system constant $k_{t}^{\prime \prime}$, required for estimating SSC from time series of vertical backscatter profiles (Eq. 20), does not depend on suspension characteristics and the range (Betteridge et al., 2008). Standard ap- 
proaches to estimate $k_{t}^{\prime \prime}$ involve special laboratory equipment and setup either for full electronic and acoustic calibration of the system, or for conducting extensive measurements in a homogeneous suspension with known sediment concentrations and scattering characteristics (Thorne and Hanes, 2002). In the absence of the means to perform these tests, Sahin et al. (2013) recently suggested a simpler alternative approach based on field data that does not require an extensive laboratory setup. The method is akin to an inverse modeling approach, based on synchronous, independent measurements of SSC, e.g., obtained with an OBS, and sediment sizes throughout the water column. The proposed approach searches for the value of $k_{t}^{\prime \prime}$ that minimizes the RMS error between a selected set of optical SSC observations and estimates:

$$
\varepsilon=\sqrt{\frac{1}{q N} \sum_{i=1}^{q} \sum_{j=1}^{N}\left(M_{O}^{i, j}-M_{A}^{i, j}\right)^{2}}
$$

where $q$ is the number of vertical levels at which optical measurements of sediment concentration are available, $N$ is the number of observations in the concentration time series, $M_{A}^{i, j}$ is the estimated (based on the acoustic backscatter) and $M_{O}^{i, j}$ is the measured sediment concentration at the location of $i$ th OBS level in $j$ th measurement interval. The count to decibel conversion factor $K_{c}$ needs to be determined in order to calculate $M_{A}^{i, j}$ through Eqs. 3 and 1. A detailed explanation of the procedure to estimate $K_{c}$ can be found in Kim et al. (2004).

\section{Field experiment}

\subsection{Site and instrumentation}

The observations were made in the lower part of the Seine Estuary, France, within the estuarine turbidity maximum (TM) in spring and autumn of 2011 during the EC2CO/Seine Aval FLUMES Experiment, dedicated to the investigation of suspended sediment dynamics in key compartments within the estuary (Fig. 2). The Seine Estuary is a macrotidal system flowing into the English Channel through a shallow bay. The farthest upstream extent of the turbidity maximum is located about $60 \mathrm{~km}$ inland, corresponding to low river flow during spring tide conditions. During periods of high freshwater discharge $\left(i 1,000 \mathrm{~m}^{3} / \mathrm{s}\right)$, the turbidity maximum zone is flushed out of the estuary mouth into Seine Bay (Verney et al., 2009). The diurnal tidal range at the estuary mouth varies between $3 \mathrm{~m}$ and $8 \mathrm{~m}$ corresponding to neap and spring tides, respectively 
(Table 1), with the tidal range of less than $1 \mathrm{~m}$ at the upstream limit of the estuary, penetrating a distance of $160 \mathrm{~km}$ inland (limited by a weir) (Verney et al., 2009). The flood-dominated tidal flow is asymmetric, characterized by longer ebb duration than flood duration, inducing higher flood velocities than ebb velocities. The deformation of the tidal wave also induces an asymmetry between slacks duration,i.e., longer high water slack than the low water slack (Brenon and Le Hir, 1999). Tidal currents largely control fine particle resuspension within the TM, with higher resuspension rates during spring tides than on neap tides (Brenon and Le Hir, 1999; Uncles et al., 2002; Deloffre et al., 2006). The river flow also plays an important role in controlling sediment dynamics of the TM. River discharge varies between $100 \mathrm{~m}^{3} / \mathrm{s}$ in summer and more than $2,200 \mathrm{~m}^{3} / \mathrm{s}$ in winter, with the mean discharge of approximately $410 \mathrm{~m}^{3} / \mathrm{s}$. (Guezenec et al., 1999). During high river discharge periods, the bulk of the fine sediment fraction is deposited in the subtidal areas seaward of the mouth. During low river discharge periods, these fine sediments are resuspended by wind-induced waves and spring tide flood currents, and a part of them are transported back into the lower estuary by flood tidal currents (Deloffre et al., 2006).

Hydrodynamics and suspended sediment characteristics were monitored during different tidal cycles at approximately $9 \mathrm{~m}$ water depth (Fig. 2), using a cluster of acoustic and optical instruments. A downward looking ADCP, mounted on a floating platform, collected current and backscatter data continuously throughout the water column. Current profiles were sampled at $1 \mathrm{~Hz}$ and recorded as 2 min ensemble averages in $20 \mathrm{~cm}$ vertical bins, with the first bin centered at about $1 \mathrm{~m}$ below the sea surface. A LISST-100X (Laser In Situ Scattering Transmissometer, Sequoia Scientific) and an OBS-3 (Optical Backscatterance Sensor, Campbell Scientific) were deployed on a profiling frame, observing the whole water column every 15 min. The LISST estimated size distributions of suspended particles at 32 class ranges between 2.5 and $500 \mu \mathrm{m}$ at $1 \mathrm{~Hz}$ samples with a path reduction module of $80 \%$ (i.e., $1 \mathrm{~cm}$ path length), and the data were processed in $50 \mathrm{~cm}$ vertical bins. The OBS, processed in $10 \mathrm{~cm}$ bins, sampled the turbidity at $2 \mathrm{~Hz}$. Water samples (from the surface and the bottom), collected every hour, were used to estimate de-flocculated particle size distributions, and for mass concentrations for calibration of the optical sensor. The OBS was re-calibrated with water samples for each data set with good linear regressions (Fig. 3). The variability of the slopes of the calibration curves seems to be associated with variable neap/spring conditions causing differences in floc packing and hence floc density. Further analysis to explain such variability is in progress, and the details will be presented elsewhere (Verney et al., in preparation). Calibration curves show no clear relation 
between floc size and the slope for each data set, justifying the negligible dependency of the OBS output signal on flocculation level. The OBS observations will be considered throughout this study as reference SSC measurements.

\subsection{Observations}

Fig. 4 shows an example for the grain size distributions measured by the LISST (spring tide in November 2011) represented as both volume size distributions and number size distributions. When represented as volume size distributions (Fig. 4a), the LISST-derived grain sizes exhibit a bimodal distributions with modes positioning around $50 \mu \mathrm{m}$ and $250 \mu \mathrm{m}$. Since the positions of the peaks are consistently larger than the median size of the de-flocculated volume particle size distribution $\left(D_{50}=9 \mu \mathrm{m}\right.$, Fig. 5), we interpret this to indicate the presence of flocculated sediment (floc mode, Verney et al., 2013). Conversion from volume fraction to number fraction distributions results in much narrower distributions with a single mode at consistently smaller than $10 \mu \mathrm{m}$ (Fig. 4b). This indicates that the existence of a few number of large flocs does not significantly affect the number distribution but dominates the volume distribution due the large volume they occupy. This behavior was consistently observed through the entire data sets analyzed and is consistent with the previous observations made in fine-sediment environments (Moore et al., 2012). Between 8:00 and 13:00 hours, existence of a larger mode than the rest of the data set in the number distribution is probably due to calmer flow conditions and lower sediment concentrations that are favorable to flocculation in energetic environments such as the Seine Estuary (Fig. 4b). We will refer to LISST mean floc size estimates over particle volume and number size distributions as $D_{m v}$ and $D_{m n}$, respectively. In order to match the particle size definition in the acoustic/SSC conversion method (Section 2.1), we represent the measured flocs by the mean values over LISST particle number size distributions $\left(D_{m n}\right)$ in the remainder of this paper. This is also consistent with the concept of scattering from the tightly-bound flocculi by Vincent and MacDonald (2015).

Data collection during spring tide on May 18th (Figs. 6a-d) is characterized by two periods of strong current activity (exceeding $2 \mathrm{~m} / \mathrm{s}$ ) during early flood and early ebb; the first occurred between 07:30 to 09:30 hours, and the second, exhibiting slightly weaker velocities, occurred between 13:30 to 16:00 hours (Fig. 6a). During these periods, a strong acoustic backscatter is recorded, suggesting the presence of large amounts of suspended matter in the water column (Fig. 6b). Qualitatively, the strength of the ADCP backscatter signal agrees with the fluctuations of OBS observations. SSC up to $2 \mathrm{~kg} / \mathrm{m}^{3}$ is observed before 7:00 hours, 
which settles for an hour with the weak currents. During flood (starting after 7:30 hours), freshly settled sediments from the previous tidal cycle are picked up by the flow (Fig. 6c). During this period, suspended particles are composed mainly of small flocs $\left(D_{m n} \simeq 5 \mu \mathrm{m}, D_{m v} \simeq 50 \mu \mathrm{m}\right.$, Fig. 6d). As the current speed decreases toward the late flood, hydrodynamic conditions become favorable to flocculation, and sediments in suspension start to settle. During this period, flocs with $D_{m n}$ around $10 \mu \mathrm{m}\left(D_{m v} \simeq 100 \mu \mathrm{m}\right)$ were observed to form throughout the water column. With the start of the ebb cycle at 14:00 hours, SSC starts increasing again, dominated by small flocs and associated with the flushing of the TM to the estuary.

Throughout the neap tide on May 23rd, suspended sediments respond to the hydrodynamic forcing in a similar manner. The intense current activity periods observed during flood and ebb are weaker than during spring tides with flow speeds less than $2 \mathrm{~m} / \mathrm{s}$ (Fig. 6e). During these periods (between 6:50-9:30 hours, and 11:00-13:30 hours), the SSC reaches up to $2 \mathrm{~kg} / \mathrm{m}^{3}$ near the bed (Fig. $6 \mathrm{~g}$ ), in agreement with the strong acoustic reflections recorded by the ADCP (Fig. 6f). Suspended sediments are mainly small flocs during these energetic periods, probably due to strong turbulence causing floc breakage. However, conditions are ideal for floc growth during slack water, with flocs larger than $10 \mu \mathrm{m}\left(D_{m v} i 100 \mu \mathrm{m}\right)$ spanning the entire water column (Fig. 6h).

Observations made in November 2011 during neap (Fig. 7a-d) and spring tides (Fig. 7e-h) are characterized by weaker currents than those observed in May. While sediment responds similarly to hydrodynamic forcing, the measured flocs are slightly larger than those measured in May, related to the lower turbulence intensity corresponding to the weaker currents.

\section{Results and discussion}

\subsection{Calibration and model performance with measured floc sizes}

For calibration of the approach presented in Section 2.2, the observations collected on November 10th are presented here, and the other sets were used to validate the results. The independent calibration checks with the other data sets resulted in similar calibration constants, ensuring the reliability of the calibration. The calculations were performed using the LISST $D_{m n}$ (Fig. 7h) and corresponding densities (Eq. 9), taking both sediment and water attenuation into account through Eqs. 5-9. A constant value $n_{f}=2$, typical for an estuarine floc (Kranenburg, 1994), was used in the calculations here. This value is consistent with the 
floc structural analysis made using the measurements of volume concentrations from LISST and the mass concentrations from OBS to estimate density and fractal dimensions of the flocs (Verney et al., 2013). The detailed investigation on the relation between the hydrodynamic forcing and the floc structure are beyond the scope of this paper, and the related results will be presented in detail elsewhere (Verney et al., in preparation). The sensitivity of the acoustic SSC estimates on the fractal structure is discussed in Section 4.4. Count to decibel conversion factor as well as the noise levels for each transducer of the ADCP employed in this study were determined in the laboratory $\left(K_{c}=0.43 \mathrm{~dB} /\right.$ count and $E_{r}=46$ counts in Eq.3).

In order to ensure the independence of $k_{t}^{\prime \prime}$ on suspension conditions, SSC measurements were divided into groups of $0.1 \mathrm{~kg} / \mathrm{m}^{3}$ ( Fig. 8a), and for each group, the optimum $k_{t}^{\prime \prime}$ giving the minimum difference between measurements and calculations was determined (Eq. 10, Fig. 8b). The value of $k_{t}^{\prime \prime}$ for different SSC classes does not show a systematic variation, and approximately $90 \%$ of the $k_{t}^{\prime \prime}$ values lie within the $\pm 30 \%$ of the average value, corresponding approximately to the standard deviation (circles and the solid line in Fig. 8b). Variation of $k_{t}^{\prime \prime}$ with range is seen in Fig. 8c for each meter from the instrument. Consistent with the SSC dependency, no systematic variation is apparent. Therefore, this consistent mean value of $k_{t}^{\prime \prime}$ was used as an instrument constant in the analyses.

The performance of the ADCP to estimate the values of SSC is presented in Figs. 9 and 10 for the data sets in May and November, respectively. The vertical profiles of SSC estimated from acosutic backscatter show a good agreement with the OBS-3 observations for different data sets, with correlation coefficients varying between $r=0.77$ and $r=0.90\left(r_{\text {average }}=0.83\right)$ and RMS errors between $\varepsilon=0.12 \mathrm{~kg} / \mathrm{m}^{3}$ and $\varepsilon=0.17 \mathrm{~kg} / \mathrm{m}^{3}$ $\left(\varepsilon_{\text {average }}=0.14 \mathrm{~kg} / \mathrm{m}^{3}\right)$. These results indicate that the newly proposed variable-density floc scatterer model (hybrid model) of Thorne et al. (2014) shows a good performance under both low and high concentration conditions during different tidal cycles, when used in conjunction with vertical mean floc size profiles (over the particle number distributions) estimated by the LISST.

\subsection{Model performance with estimated floc sizes}

Application of the method to estimate SSC profiles (Section 2.1) requires information on the vertical distribution of the mean sediment size (floc size), in addition to the backscatter intensity profiles. While commercial current profilers are commonly used to measure current and backscatter intensity profiles, floc size measurements with high vertical resolution are not practical for long periods. 
It is known that floc formation is dominantly controlled by flow turbulence and sediment availability (e.g., McCave, 1984; Dyer and Manning, 1999; Hill et al., 2001; Winterwerp, 2002; Verney et al., 2009; Safak et al., 2013; Sahin, 2014). Therefore, floc size profiles may be estimated from turbulence intensity profiles extracted from the current velocity profiles when detailed sediment size measurements are not available.

The effect of turbulence on floc formation can be represented by the shear rate $G\left(\mathrm{~s}^{-1}\right)$ (Berhane et al., 1997; Dyer and Manning, 1999; Safak et al., 2013; Sahin, 2014)

$$
G=\left(\frac{\varepsilon}{v}\right)^{1 / 2}
$$

where $\varepsilon=\frac{u_{*}^{3}}{\kappa z}$ is the dissipation rate with $u_{*}$ the friction velocity, $\kappa=0.41$ the von Karman's constant and $z$ the distance above bed. Assume a logarithmic law of the wall for unstratified turbulent boundary layer

$$
u(z)=\frac{u_{*}}{\kappa} \ln \left(\frac{z}{z_{0}}\right)
$$

where $u$ is the horizontal velocity, and $z_{0}$ is a function of bottom roughness at which the velocity is zero. The parameters $u_{*}$ and $z_{0}$ in Eq. 12 can be estimated iteratively based on the values providing the best-fit between logarithmic profiles and the measured current velocity profiles $u(z)$ outside the wave boundary layer (Lacy et al., 2005; Safak et al., 2013). This procedure was applied to the ADCP velocity profiles in order to calculate the friction velocities for all the data sets. The valid logarithmic zone spanned the entire profile for about $75 \%$ of the measurement bursts. The $u_{*}$ estimates were then used to calculate the dissipation rate and the shear rate throughout the vertical axis using Eq. 11.

Relationship between the calculated shear rates and the LISST floc sizes $\left(D_{m n}\right)$ is presented in Fig. 11. Flocs of around $10 \mu \mathrm{m}$ has the largest frequency of occurrences at $\mathrm{G} \simeq 1 \mathrm{~s}^{-1}$. For higher shear rates, the frequency of occurrences of smaller flocs begin to increase (Fig. 11a). For all data sets, floc size shows an increasing trend with increasing shear rate up to $\sim 1 \mathrm{~s}^{-1}$. This trend is reversed for larger shear rate values, and the floc size starts decreasing with increasing shear rate up to $\sim 13 \mathrm{~s}^{-1}$. Floc size maintains a constant value of around $5 \mu \mathrm{m}$ at higher shear rates (Fig. 11b). The floc size-shear rate relationships shown in the Fig. 11 is consistent with the previous studies (e.g., Berhane et al., 1997; Dyer, 1989; Sahin, 2014), and it allows for estimation of the floc size profiles when detailed sediment size measurements are not available.

The floc size profiles estimated using the relationship shown in Fig. 11b (thick blue curve) are in good 
agreement between the mean floc sizes measured by the LISST, with RMS errors ranging from 1.6 microns to 2.2 microns for different data sets (Figs. 12-13a and b). Resulting SSC values are in the same range as the data, and represent well the time evolution of the measurements. Average RMS error inceases slightly from $0.14 \mathrm{~kg} / \mathrm{m}^{3}$ to $0.17 \mathrm{~kg} / \mathrm{m}^{3}$ when the estimated floc sizes are used instead of the measured ones to estimate SSC profiles. These findings indicate that using estimated floc sizes in calculations can provide reasonable SSC profiles when detailed floc size measurements are not available.

\subsection{Previous models for solid scatterers}

Mean floc sizes over particle number size distributions exhibit values lower than $15 \mu \mathrm{m}$ throughout the water column during different tidal cycles (Figs. 6d, h; and 7d, h). Based on the model of Thorne et al. (2014), although the scattering properties (represented by the parameter $k_{s}$ ) of large flocs may be significantly different from those of the solid particles, the values of $k_{s}$ reconcile as the particle size decreases (Fig. 14). For the mean floc size $\left(D_{m n}\right)$ range observed here, $k_{s}$ values for flocs $\left(k_{s f}\right)$ maintain values close to those (less than three times difference) of solid scatterers $\left(k_{s s}\right)$, suggesting that the previous models based on the solid particle-scatterer assumption may also provide acceptable results when used with the measured flocs. To test this, we repeated the calculations using the expressions given by Moate and Thorne (2013) for sandy particles (assuming a constant density, $\rho=2650 \mathrm{~kg} / \mathrm{m}^{3}$ ). The solid particle-scatterer model also performs satisfactory during energetic periods (during flood and ebb), when $D_{m n}$ is consistently lower than $5 \mu \mathrm{m}$, during both Neap (Fig. 15a-d) and Spring tides (Fig. 15a-d) in November. During these high concentration periods, the new hybrid model (floc-scatterer model) predicts the SSC values with $0.19 \mathrm{~kg} / \mathrm{m}^{3} \mathrm{RMS}$ error on average, while the error is $0.20 \mathrm{~kg} / \mathrm{m}^{3}$ for the solid-scatterer model. For this particle size range, the scattering characteristics of solid particles and flocs become remarkably close with the ratio $k_{s s} / k_{s f}$ less than 1.5. During the periods characterized with lower concentrations and larger flocs (during slack), difference between the scattering properties is larger $\left(k_{s s} / k_{s f} \sim 3\right)$, and the solid particle-scatterer model consistently underestimates the concentrations while the hybrid model is able to reconstruct well the SSC profiles. During these periods, the RMS errors for the hybrid and the solid-scatterer models are $0.02 \mathrm{~kg} / \mathrm{m}^{3}$ and 0.042 $\mathrm{kg} / \mathrm{m}^{3}$, respectively. The percentage errors demonstrate more clearly the performances of these two models due to large differences between concentrations during flood/ebb (high-concentration) and slack water (lowconcentration) conditions (Figs. 15e and 16e). While the hybrid model predicts high and low concentrations 
with around $10 \%$ and $18 \%$ errors (average of all the data sets), respectively, the solid-scatterer model's performance is significantly different under high concentration (small-floc) and low-concentration (large-floc) conditions with $15 \%$ and $40 \%$ errors, respectively.

In terms of mass sediment fluxes (per unit width), determined by integrating the product of velocity and SSC data over the depth of the water column, floc-scatterer model performs better than the solid-scatterer model under both low and high energy conditions (Figs. 15f and 16f). The percentage errors in flux estimates yield similar values to those obtained for the SSC estimates (Figs. 15e and 16e). The tidally averaged RMS errors are $2 \mathrm{~kg} / \mathrm{m} / \mathrm{s}$ and $3.4 \mathrm{~kg} / \mathrm{m} / \mathrm{s}$ for floc-scatterer and solid-scatterer models, respectively. The sediment flux values are remarkably low during low energy periods characterized with large flocs, where the the flocscatterer model's performance is significantly better than the previous solid-scatterer model. On average, the sediment flux values during these low energy periods are about 10 times lower than the values during high energy periods. While the percentage error between the two alternative methods are considerably high during these periods, the difference in sediment fluxes is negligibly low due to lack of both high velocities and SSCs.

These results suggest that previous models given for solid particles may perform closer to the variable density floc model during energetic events associated with strong currents, small flocs and large concentrations. This is because of the fact that mean floc size values become very low $\left(D_{m n} \simeq 5 \mu \mathrm{m}\right)$ when they are represented by the particle number distributions under field conditions in muddy environments. The improvement made by the new floc-scaterrer model is much more apparent during less energetic periods characterized by larger flocs. However, the contribution of the sediment suspended during these less energetic periods to the total sediment flux may be considered negligible.

\subsection{Sensitivity to fractal structure}

The fractal dimension was assumed constant and set to $n_{f}=2$, a typical value for an estuarine floc. The value of the fractal dimension may change from 1.4 for very fragile flocs to larger than 2.2 for strong estuarine flocs (Kranenburg, 1994). Based on field measurements in estuarine environments and on intertidal mudflats, Dyer and Manning (1999) show that the value of the fractal dimension depends strongly on flow conditions and suspended sediment concentration. The floc fractal structure affects the important floc characteristics such as the floc density and strength, and the collision-induced shear stresses. In order to investigate the 
sensitivity of the inversion algorithm to the value of the fractal dimension, calculations were repeated using the measured floc sizes with different fractal dimensions $n_{f}=1.5$ and $n_{f}=2.3$. Fig. 17 shows the relation between the measured SSC and the estimated ones using different fractal dimensions during neap tide in November (November 3rd). The model with $n_{f}=2$ underestimates SSC for low concentrations (i.e., below $0.2 \mathrm{~kg} / \mathrm{m}^{3}$ ) and overestimates SSC for high concentration conditions (i.e., above $1 \mathrm{~kg} / \mathrm{m}^{3}$ ). The model with $n_{f}=1.5$ performs better at low concentrations, while the model with $n_{f}=2.3$ reconstruct the observations well when the SSC is high. In other words, the model with increasing fractal dimension performs better as the concentration increases. This behavior is consistent with the concept of a cohesive sediment particle undergoing aggregation processes. Our observations suggest a negative correlation between SSC and the floc size (Figs. 6 and 7). Low concentrations indicate the existence of larger but more fragile flocs, which are expected to have lower fractal dimensions. More robust smaller flocs observed during energetic, highconcentration conditions are typically have larger fractal dimensions (Kranenburg, 1994). This behavior can also be explained by the dependence of floc density on the fractal dimension. According to Eq. 9, floc density scales with $D_{f}^{n_{f}-3}$. Hence, for a constant floc size, floc density increases with increasing fractal dimension resulting in an increase in $f_{f}$ (or the acoustic sensitivity, Fig. 1), and therefore in $k_{s}$ (Eq. 14). Based on Eq. 20, increasing $k_{s}$ yields lower SSC estimates. Consequently, using larger fractal dimensions in the model results in lower concentration estimates.. Although the results presented here do not suggest a significant dependence on fractal dimension, they highlight that using a variable fractal dimension may increase the quality of the estimates.

\section{Conclusions}

Observations of the vertical profiles of SSC, floc size, and the backscatter intensity of the acoustic signal collected in the lower part of the Seine Estuary (France) during May and November 2011, covering both neap and spring tides were used to study the behavior of the acoustic signal of suspended cohesive particles. In addition to the acoustic backscatter profiles, the OBS and the LISST provided direct SSC (sometimes exceeding $2 \mathrm{~kg} / \mathrm{m}^{3}$ ) and floc size measurements within the entire water column, respectively. The vertical distribution of observations provides a detailed basis of comparison and validation of the results of backscatter analysis and interpretation. The newly proposed hybrid model (Thorne et al., 2014), which is based on variable particle density to describe the scattering of flocculated sediments, is tested to calculate the scat- 
tering parameters needed to estimate the SSC profiles, for the first time in a field application. The resulting SSC profiles are in agreement with the OBS point measurements under a variety of field conditions, confirming the applicability of the new hybrid model in the field when detailed particle size measurements are available.

The model requires information on the vertical distribution of the mean sediment size (floc size), which is difficult to measure, and mostly unavailable over long periods. Since floc growth and breakage are controlled by the flow turbulence level, floc sizes may be estimated under known turbulence conditions. Turbulent shear profiles were estimated using the current velocity profiles measured by the ADCP. The friction velocities were estimated by fitting the logarithmic profiles in a least-square sense to the current velocity profiles, outside the wave boundary layer, which can then be used to approximate the dissipation of turbulent kinetic energy and the turbulent shear profiles. The relationship observed between the shear rate and the floc size allows for estimation of floc sizes based on the flow conditions.Using estimated floc sizes in calculations provide reasonable SSC profiles when detailed floc size measurements are not available.

Sediment size is defined by the mean value over the particle number size distribution in the model. The mean floc size values over particle number size distributions are consistently lower $15 \mu \mathrm{m}$ throughout the water column. During energetic events associated with strong currents, the observed floc sizes are around $5 \mu \mathrm{m}$, for which the scattering properties of flocs and the solid particles are remarkably close. Therefore, previous models given for solid particles perform almost as well as the variable density floc model during these periods. The improvement made by the new floc-scaterrer model is apparent during less energetic periods characterized by larger flocs, as the floc scattering properties differ from those of solid particles with increasing sediment size. This result is probably universal since previous observations in different geographical locations indicate a similar mean sediment size range, when represented by the particle number size distributions (e.g., The Romans-sur-Isre, France (Moore et al., 2012); Atchafalaya Shelf, Gulf of Mexico (Safak et al., 2010)).

The observations and the results obtained at a fixed geographic location during different tidal cycles are consistent. Some of the errors in SSC estimates can be attributed to the uncertainties related to the reference estimates of SSC profiles based on OBS data and uncertainties related to the particle size and density estimates based on shear rate profiles. Salinity-induced stratification, which is likely to be strongest during the transition between flood and ebb tides, might affect the results inferred here, since it is likely to have 
an effect on floc dynamics, overall backscatter from the ADCP, and the shear stress estimated from the logarithmic profiles. The site-dependence should also be investigated since the flocs of the same size may have different densities depending on the sediment characteristics of the site (e.g., organic content, fractal dimension). Other parameters affecting the floc scattering characteristics, i.e, fluid heuristic formulation coefficients, sound velocity in a fluid scatterer and in primary particles, were set to constant values used by MacDonald et al. (2013) and Thorne et al. (2014). Future efforts should focus on validation of the acoustic behavior inferred here with as many supporting measurements as possible to constrain the model input parameters at different locations under different conditions.

\section{Appendix}

Under incoherent scattering conditions, the root-mean-square backscattered voltage $V(r)$, at range $r$, from a piston transceiver, can be written as (Sheng and Hay, 1988; Hay and Sheng, 1992; Thorne et al., 1993; Thorne and Hanes, 2002; Moore et al., 2012),

$$
V(r)=\frac{k_{s}(r) k_{t}}{r \psi(r)} M(r)^{1 / 2} e^{-2 r \alpha(r)},
$$

with

$$
k_{t}=R T_{v} p_{0} r_{0}\left\{\frac{3 \tau c}{16}\right\}^{1 / 2} \frac{0.96}{k a_{t}}, \quad k_{s}(r)=\frac{\left\langle f_{f}(r)\right\rangle}{\sqrt{\langle a(r)\rangle \rho(a)}},
$$

where $R$ is the transducer receive sensitivity, $T_{v}$ is the voltage transfer function of the system. Eq. 13 can be rearranged in terms of pressure using the relationship $V=R T_{v} p_{r m s}$, where $p_{r m s}$ is the the root-mean-square backscattered pressure (Moore et al., 2012),

$$
p_{r m s}=p_{0} r_{0} \frac{k_{s} k_{t}^{\prime}}{r \psi} M^{1 / 2} e^{-2 r \alpha}
$$

where

$$
k_{t}^{\prime}=\left\{\frac{3 \tau c}{16}\right\}^{1 / 2} \frac{0.96}{k a_{t}} .
$$


Sound pressure level in decibels can be determined using

$$
I_{d B}=20 \log _{10}\left(\frac{p_{r m s}}{p_{r e f}}\right)
$$

where $p_{r e f}$ is the reference pressure at a reference distance $r_{0}$ (for the instrument used in this study, ADCP, $p_{r e f}=1 \mu \mathrm{Pa}$ and $\left.r_{0}=1 \mathrm{~m}\right)$ Substituting Eq. 15 into Eq. 17 yields

$$
I_{d B}=10 \log _{10}\left(\frac{p_{0}^{2}}{p_{r e f}^{2}} \frac{k_{s}^{2} k_{t}^{\prime 2}}{\psi^{2} r^{2}} M e^{-4 r \alpha}\right)=10 \log _{10}\left(\frac{p_{0}^{2}}{p_{r e f}^{2}}\right)+10 \log _{10}\left(\frac{k_{s}^{2} k_{t}^{\prime 2}}{\psi^{2} r^{2}} M e^{-4 r \alpha}\right)
$$

The first term on the RHS is the term commonly referred to as the source level, which is the intensity of emitted signal. The absolute level of the source level SL (in dB, i.e. the transmitted power) is also rarely known accurately (e.g., Holdaway et. al., 1999). Since it is invariant in time and height above the bed, it can be included in the instrument constant, which needs to be determined by calibration,

$$
k_{t}^{\prime \prime}=\left\{\frac{3 \tau c}{16}\right\}^{1 / 2} \frac{0.96}{k a_{t}} \frac{p_{0}}{p_{r e f}} .
$$

Reaaranging Eqs. 18 and 19, finally the equation to estimate $M(r)$ takes the following form,

$$
M(r)=\left\{\frac{10^{I_{d B} / 20} r \psi}{k_{s} k_{t}^{\prime \prime}}\right\}^{2} e^{4 r \alpha}
$$

\section{Acknowledgments}

The FLUMES experiment was funded by the Seine Aval Research Program (FLUMES2.1) and the INSU EC2CO research program (FLUMES2.2). The authors thank the crew of the R/V Cte de la Manche for their kind assistance during field surveys.

\section{References}

Berhane, I., Sternberg R.W., Kineke G.C., Milligan T.G., Kranck, K., 1997. The variability of suspended aggregates on the Amazon Continental Shelf. Continental Shelf Research 17, 267-285. 
Betteridge, K. F. E., P. D. Thorne, and R. D. Cooke (2008), Calibrating multi-frequency acoustic backscatter systems for studying near-bed suspended sediment transport processes, Cont. Shelf Res., 28, 227-235.

Brenon, I., and P. Le Hir (1999), Modelling the turbidity maximum in the Seine estuary (France): identification of formation processes, Estuar. Coast. Shelf Sci., 49 (4), 525-544

Crawford, A.M., and A.E. Hay (1993), Determining suspended sand size and concentration from multifrequency acoustic backscatter, J. Acoust. Soc. Am., 94 (6), 2247-2254.

Deines, K. L. (1999), Backscatter estimation using broadband acoustic Doppler current profilers, Proc. Sixth Working Conf. on Current Measurement, San Diego, CA, IEEE, 249-253.

Deloffre, J., R. Lafite, P. Lesueur, R. Verney, S. Lesourd, A. Cuvilliez, and J. Taylor (2006), Controlling factors of rhythmic sedimentation processes on an intertidal estuarine mudflat. Role of the turbidity maximum in the macrotidal Seine estuary, France, Mar. Geol., 255, 151-164.

Downing, A., P.D. Thorne, and C.E. Vincent (1995), Backscattering from a suspension in the near field of a piston transducer, J. Acoust. Soc. Am., 97 (3), 1614-1620.

Dyer, K. R., 1989. Sediment processes in estuaries: future research requirements. Journal of Geophysical Research 97, 14327-14339.

Dyer, K. R., and A.J. Manning (1999), Observation of size, settling velocity and effective density of flocs, and their fractal dimensions, J. Sea Res., 41, 87-95.

Francois, R.E., and G.R. Garrison (1982), Sound absorption based on ocean measurements. Part I: pure water and magnesium sulfate contributions, J. Acoust. Soc. Am., 72, 896-907.

Fugate, D.C., and C.T. Friedrichs (2002), Determining concentration and fall velocity of estuarine particle populations using ADV, OBS and LISST, Cont. Shelf Res., 22, 1867-1886.

Gartner, J.W. (2004), Estimating suspended solids concentrations from backscatter intensity measured by acoustic Doppler current profiler in San Francisco Bay, California, Mar. Geol., 211, 169-187.

Gostiaux, L., and H. (2010), Extracting meaningful information from uncalibrated backscattered echo intensity data, Journal of Atmospheric and Oceanic Technology, 27, 943-949. 
Guezenec, L., R. Lafite, J.-P. Dupont, R. Meyer, and D. Boust (1999), Hydrodynamics of suspended particulate matter in the tidal freshwater zone of a macrotidal estuary (the Seine estuary, France), Estuaries, 22:717-727.

Ha, H.K., W.-Y. Hsu, J.-Y. Maa, Y. Shao, and C. Holland (2009), Using ADV backscatter strength for measuring suspended cohesive sediment concentration, Cont. Shelf Res., 29 (10), 1310-1316.

Ha, H.K., J.P. -Y. Maa, K. Park, and Y.H. Kim (2011), Estimation of high-resolution sediment concentration profiles in bottom boundary layer using pulse-coherent acoustic Doppler current profiles, Mar. Geol., 279 (2011), 199-209.

Hay, A.E., and J. Sheng (1992), Vertical Profiles of Suspended Sand Concentration and Size From Multifrequency Acoustic Backscatter, J. Geophys. Res. Oceans, 97, C10, doi:10.1029/92JC01240.

Hill, P.S., G. Voulgaris, and J.H. Trowbridge (2001), Controls on floc size in a continental shelf bottom boundary layer. J. Geophys. Res., 106, C5, 9543-9549.

Hoitink, A.J.F., and P. Hoekstra (2005), Observations of suspended sediment from ADCP and OBS measurements in a mud-dominated environment, Coastal Eng., 52, 103-118.

Holdaway, G.P., Thorne P. D., Flatt D., Jones S.E., Prandle D., 1999. Comparison between ADCP and transmissometer measurements of suspended sediment concentration. Cont. Shelf Res., 19, 421-441.

Kaye, G.W.C., and T.H. Laby (1986), Tables of physical and chemical constants. Longman, UK, pp. 477.

Kim, Y.H., Gutierrez, B., Nelson, T., Dumars, A., Maza, M., Perales, H., Voulgaris, G. (2004), Using the acoustic Doppler current profiler (ADCP) to estimate suspended sediment concentration. Technical Report CPSD \#04-01, Department of Geological Sciences, University of South Carolina, SC, 20 p.

Kineke G.C., and R.W. Sternberg (1992), Measurements of high concentration suspended sediments using the optical backscatterance sensor, Mar. Geol., 108 (3-4): 253-258.

Kranenburg, C. (1994), On the fractal structure of cohesive sediment aggregates, Estuar. Coas. Shelf Sci., $39,451-460$. 
Lacy, J.R., Sherwood, C.R., Wilson, D.J., Chisholm, T.A., Gelfenbaum, G.R., 2005. Estimating hydrodynamic roughness in a wave-dominated environment with a high-resolution acoustic Doppler profiler. Journal of Geophysical Research 110, C06014, doi: 10.1029/2003JC001814.

Le Hir, P., A. Ficht, R. Silva Jacinto, P. Lesueur, J.-P. Dupont, R. Lafite, I. Brenon, B. Thouvenin, and P. Cugier (2001), Fine sediment transport and accumulations at the mouth of the Seine Estuary (France), Estuaries, 24(6B), 950-963.

Lynch, J.F., J.D. Irish, C.R. Sherwood and Y.C. Agrawal (1994), Determining suspended sediment particle size information from acoustical and optical backscatter measurements, Cont. Shelf Res., 14, 1139-1165.

MacDonald, I.T., C.E. Vincent, P.D. Thorne, and P.D. Moate (2013), Acoustic scattering from a suspension of flocculated sediments, J. Geophys. Res. Oceans, 118, 1-14, http://dx.doi.org/10.1002/jgrc.20197.

McAnally, W.H., and A. Mehta, (2000), Aggregation rate of fine sediment, J. Hydraul. Eng., 126, 883-892.

McCave, I.N. (1984), Size spectra and aggregation of suspended particles in the deep ocean, Deep-Sea Res $31: 329-352$

Moate, B.D., and P.D. Thorne (2013), Scattering from suspended sediments having different and mixed mineralogical compositions: comparision of laboratory measurements and theoretical predictions, J. Acoust. Soc. Am., 133 (3), 1320-1334.

Moore, S.A., J. Le Coz, D. Hurther, and A. Paquier (2012), On the application of horizontal ADCPs to suspended sediment transport surveys in rivers, Cont. Shelf Res., 46, 50-63.

Rouhnia, M., A. Keyvani, and K. Strom (2014), Do changes in the size of mud flocs affect the acoustic backscatter values recorded by a Vector ADV?, Cont. Shelf Res., 84, 84-92, doi: 10.1016/j.csr.2014.05.015

Safak, I., A. Sheremet, M. A. Allison, T. J. Hsu (2010), Bottom turbulence on the muddy Atchafalaya Shelf, Louisiana, USA, J. Geophys. Res. Oceans, 115, doi:10.1029/2010JC006157.

Safak, I., M.A. Allison, and A. Sheremet (2013), Floc variability under changing turbulent stresses and sediment availability on a wave energetic muddy shelf, Cont. Shelf Res., 53, 1-10, http://dx.doi.org/10.1016/j.csr.2012.11.015. 
Sahin, C., I. Safak, T.-J. Hsu, and A. Sheremet (2013), Observations of suspended sediment stratification from acoustic backscatter in muddy environments, Mar. Geol., 336, 24-32, http://dx.doi.org/10.1016/j.margeo.2012.12.001.

Sahin, C. (2014), Investigation of the variability of floc sizes on the Louisiana Shelf using acoustic estimates of cohesive sediment properties, Mar. Geol., 353, 55-64, http://dx.doi.org/10.1016/j.margeo.2014.03.022.

Sheng, J., and A.E. Hay (1988), An examination of the spherical scatter approximation in aqueous suspensions of sand, J. Acoust. Soc. Am., 83, 598-610.

Shields, F. D. (2010), Aquatic habitat bottom classification using ADCP, J. Hydraul. Eng., 136, 336-342, doi:10.1061/(ASCE)HY.1943-7900.0000181.

Thorne, P. D., C. E. Vincent, P. J. Harcastle, S. Rehman and N. Pearson (1991), Measuring suspended sediment concentrations using acoustic backscatter devices, Mar. Geol., 98, 7-16.

Thorne, P.D., P.J. Hardcastle, and R.L. Soulsby (1993), Analysis of acoustic measurements of suspended sediments, J. Geophys. Res. Oceans, 98 (C1), 899-910.

Thorne, P. D. and P. J. Hardcastle (1997), Acoustic measurements of suspended sediments in turbulent currents and comparison with in-situ samples, J. Acoust. Soc. Am., 101, 2603-2614.

Thorne, P.D., and D.M. Hanes (2002), A review of acoustic measurement of small-scale sediment processes, Cont. Shelf Res., 22, 603-632.

Thorne, P.D., and R. Meral (2008), Formulations for the scattering properties of suspended sandy sediments for use in the application of acoustics to sediment transport processes. Cont. Shelf Res., 28, 309-317.

Thorne, P.D., I.T. MacDonald, and C.E. Vincent (2014), Modelling acoustic scattering by suspended flocculating sediments, Cont. Shelf Res., in press, http://dx.doi.org/10.1016/j.csr.2014.07.003.

Uncles, R.J., J.A. Stephens, and R.E. Smith (2002), The dependance of estuarine turbidity on tidal intrusion length, tidal range and residence time, Cont. Shelf Res., 22 (11-13), 1835-1856.

Urick, R.J. (1948), The absorption of sound in irregular particles, J. Acoust. Soc. Am., 20 (3), 283-289. 
Verney, R., R. Lafite, and J. Brun-Cottan (2009), Flocculation potential of estuarine particles: The importance of environmental factors and of the spatial and seasonal variability of suspended particulate matter, Estuar. Coast., 32, 678-693.

Verney, R., R. Lafite, J.C. Brun-Cottan, and P. Le Hir (2011), Behaviour of a floc population during a tidal cycle: Laboratory experiments and numerical modelling, Cont. Shelf Res., 31, S64-S83, doi: 10.1016/j.csr.2010.02.005.

Verney, R., G. Voulgaris, A. Manning, J. Deloffre, and P. Bassoullet (2013), Quantifying suspended particulate matter (SPM) dynamics in estuaries: combining acoustic and optical approaches, Proceedings of the International Conference on Cohesive Sediment Transport Processes (INTERCOH), October 2013, Gainesville, Florida.

Vincent C.E., and I.T. MacDonald (2015), A flocculi model for the acoustic scattering from flocs, Cont. Shelf Res., 104, 15-24, http://dx.doi.org/10.1016/j.csr.2015.05.002

Voulgaris, G., and S. Meyers (2004), Temporal variability of hydrodynamics, sediment concentration and sediment settling velocity in a tidal creek, Cont. Shelf Res., 24, 1659-1683.

Wang, Y. P., G. Voulgaris, Y. Li, Y. Yang, J. Gao, J. Chen, and S. Gao (2013), Sediment resuspension, flocculation, and settling in a macrotidal estuary, J. Geophys. Res. Oceans, 118, 5591-5608, doi:10.1002/jgrc.20340.

Winterwerp, J. C. (2002), On the flocculation and settling velocity of estuarine mud, Cont. Shelf Res., 22, 1339-1360, doi:10.1016/S0278-4343(02)00010-9. 


\begin{tabular}{|c|c|}
\hline Date (2011) & Tidal range $(\mathrm{m})$ \\
\hline \hline May 18th & 7.00 \\
\hline May 23rd & 5.05 \\
\hline November 3rd & 3.45 \\
\hline November 10th & 5.85 \\
\hline
\end{tabular}

Table 1: Tidal ranges for different data sets
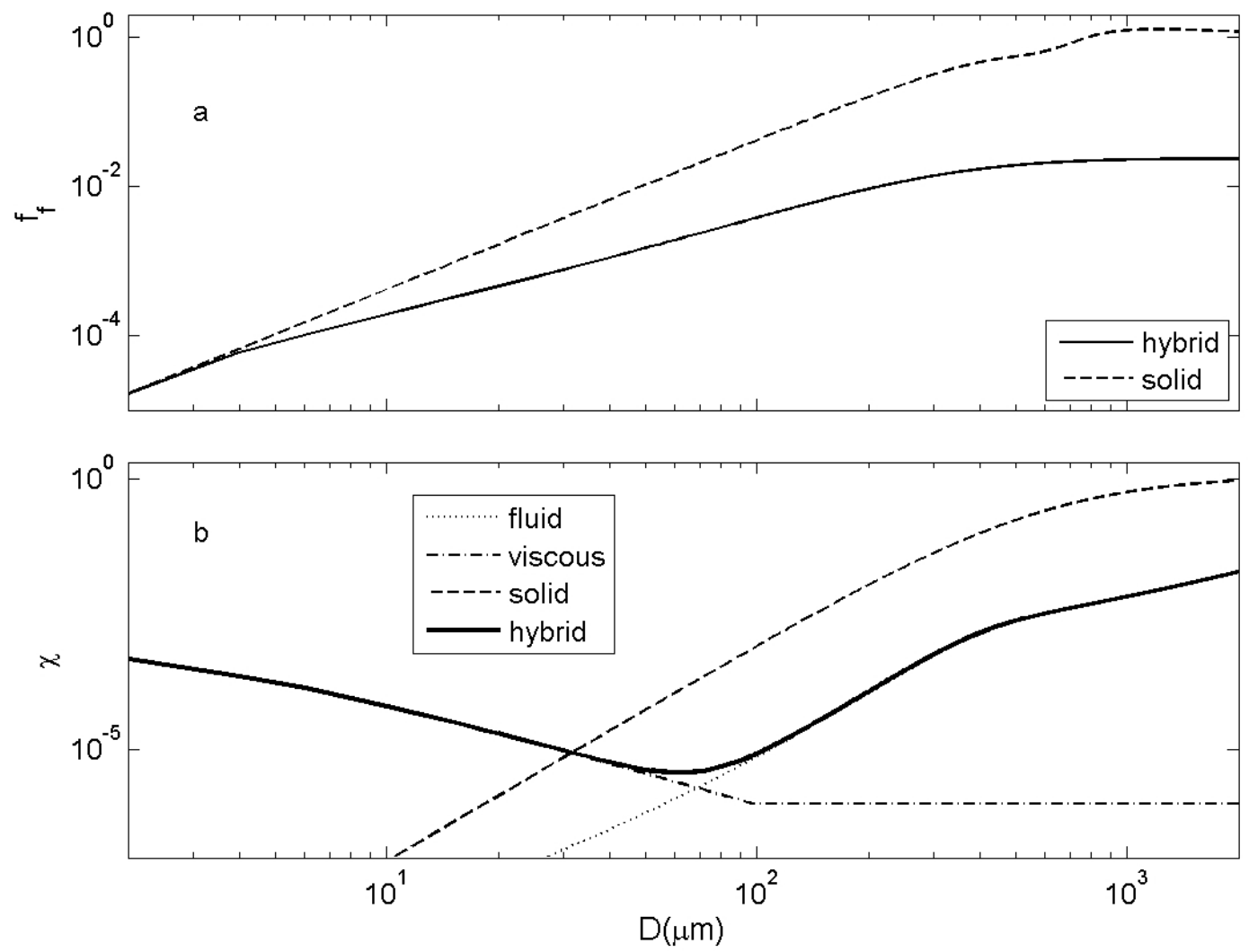

Figure 1: Variation of (a) the form function, $f_{f}$, and (b) the normalized total scattering cross section, $\chi$, with particle size for a solid, fluid and hybrid scatterer. 

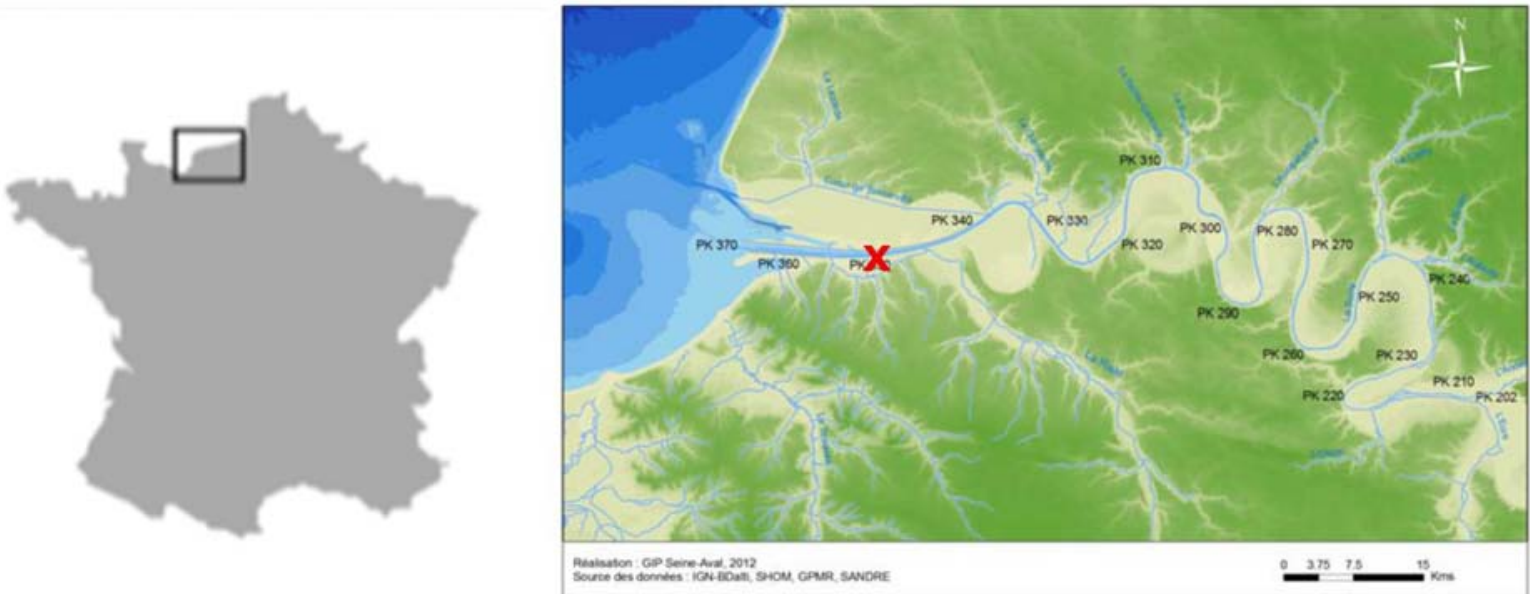

Figure 2: The approximate location of the sampling station (red ' $x$ ') in the lower reaches of the Seine estuary, France $\left(49.4365^{\circ}\right.$ latitude North, $0.3187^{\circ}$ longitude East).
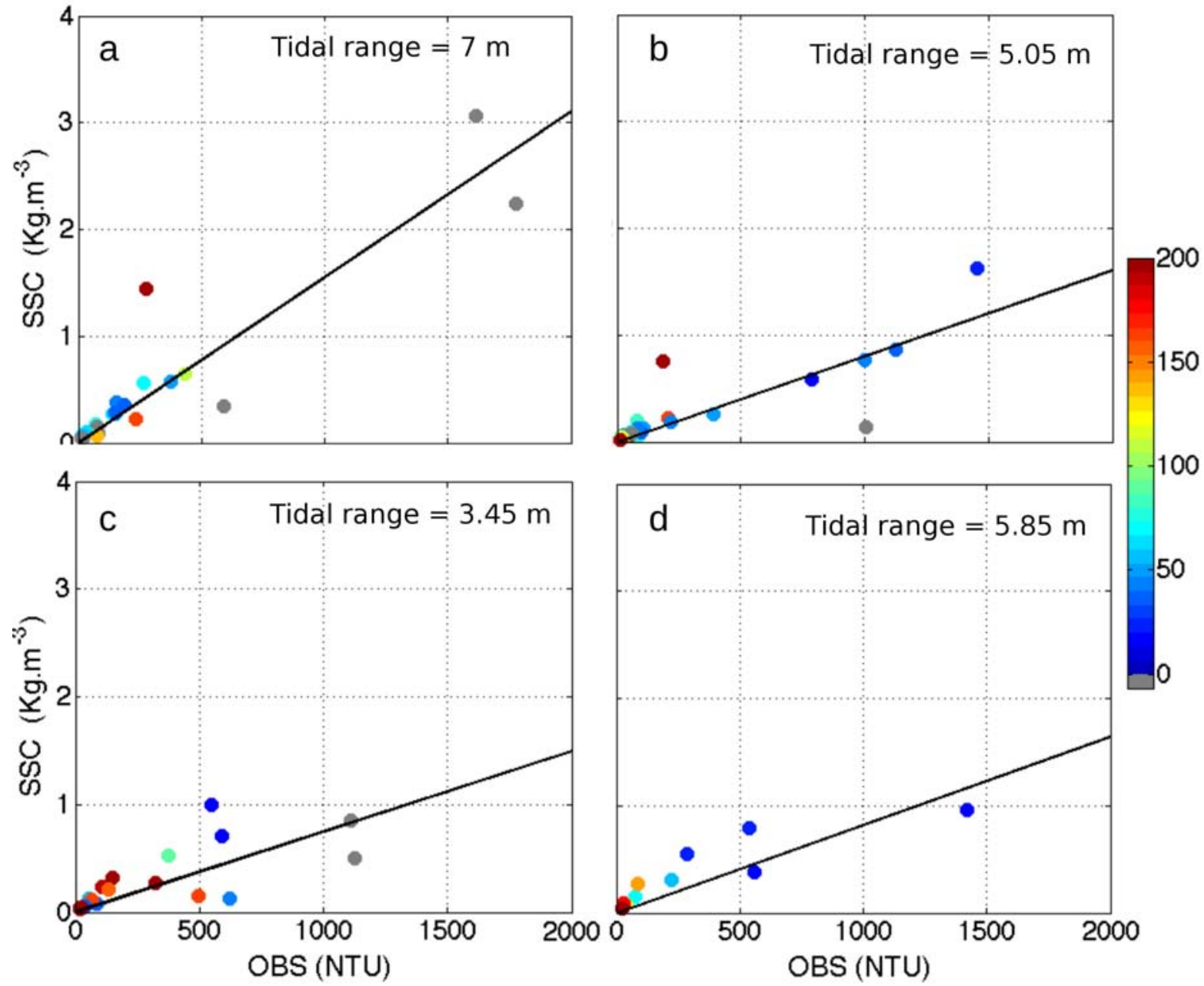

Figure 3: Calibration of the OBS for different data sets: (a) May 18th, (b) May 23rd, (c) November 3rd, (d) November 10th. Colorbar indicates the floc sizes. Gray points correspond to the data with no floc size information available. 

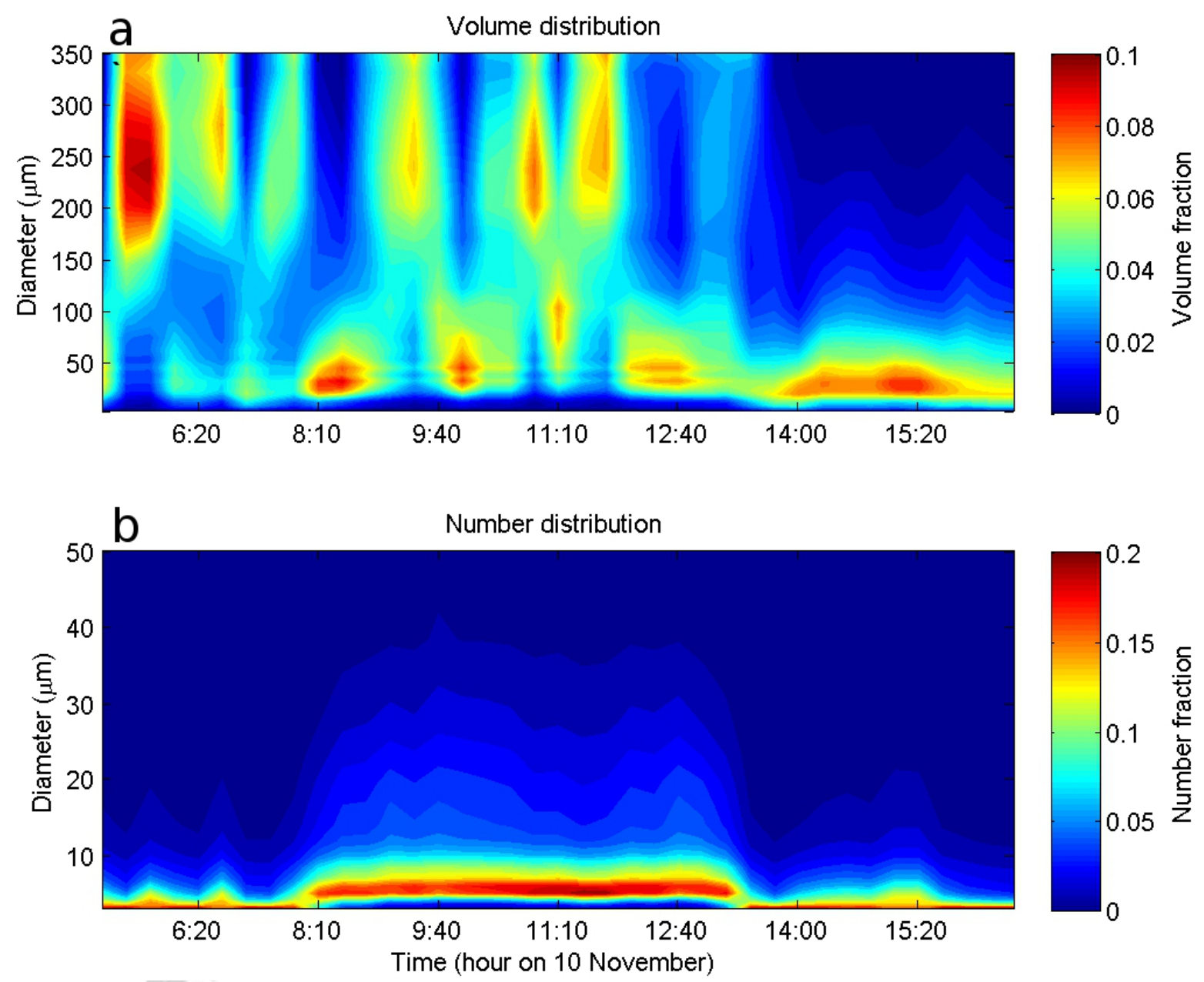

Figure 4: Example of grain size distributions measured by the LISST (November 10th) represented as (a) volume fraction and (b) number fraction distributions. The distributions show the normalized values, rather than the units micro-litres and numbers of particles per liter. 


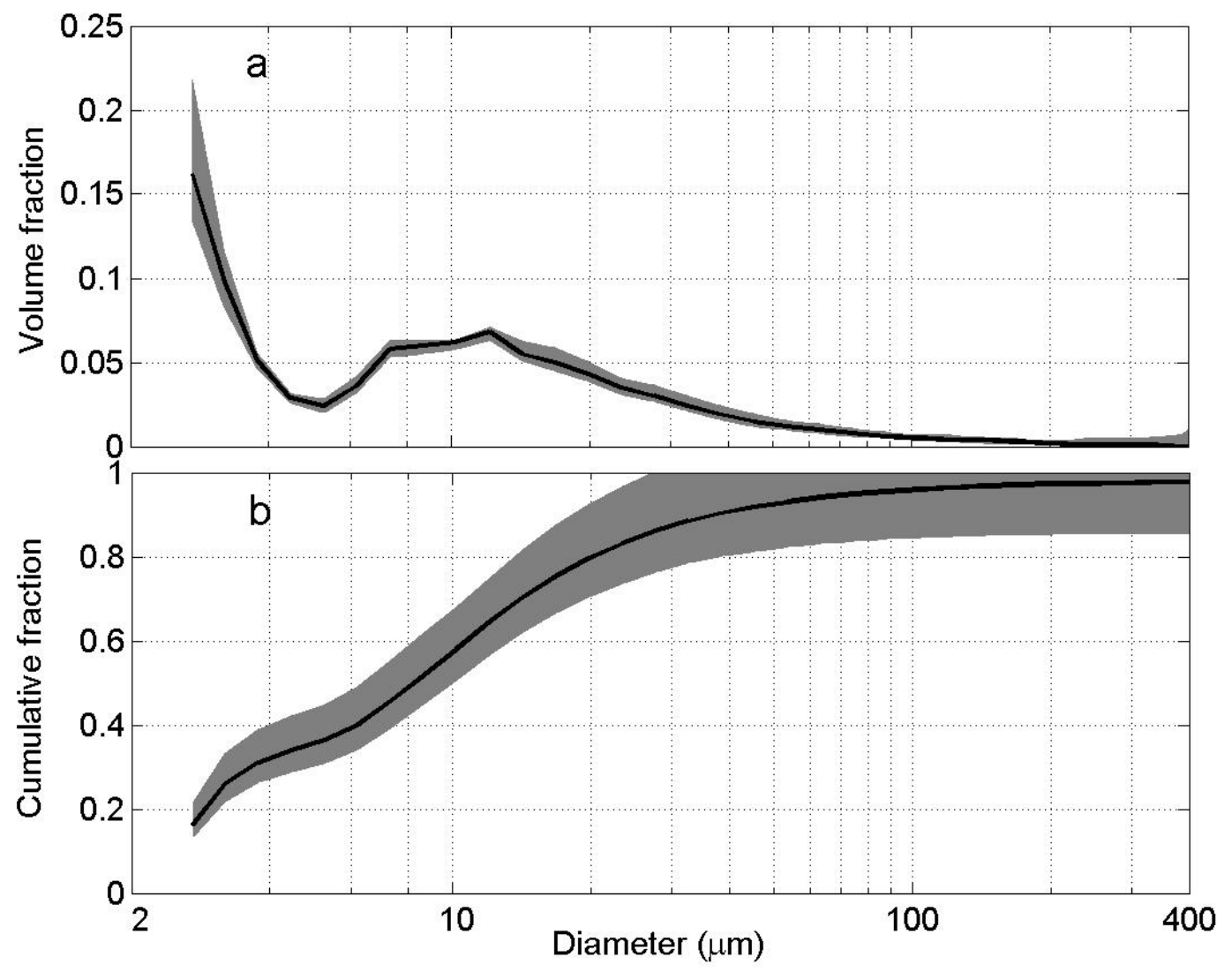

Figure 5: An example of a de-flocculated particle size distributions (based on samples taken on May 18th), (a) volume fraction and (b) cumulative fraction distributions. Black solid lines represent the median of all samples per size classes. Upper and lower limits of gray shades correspond to 10th and 95th percentiles, respectively. 

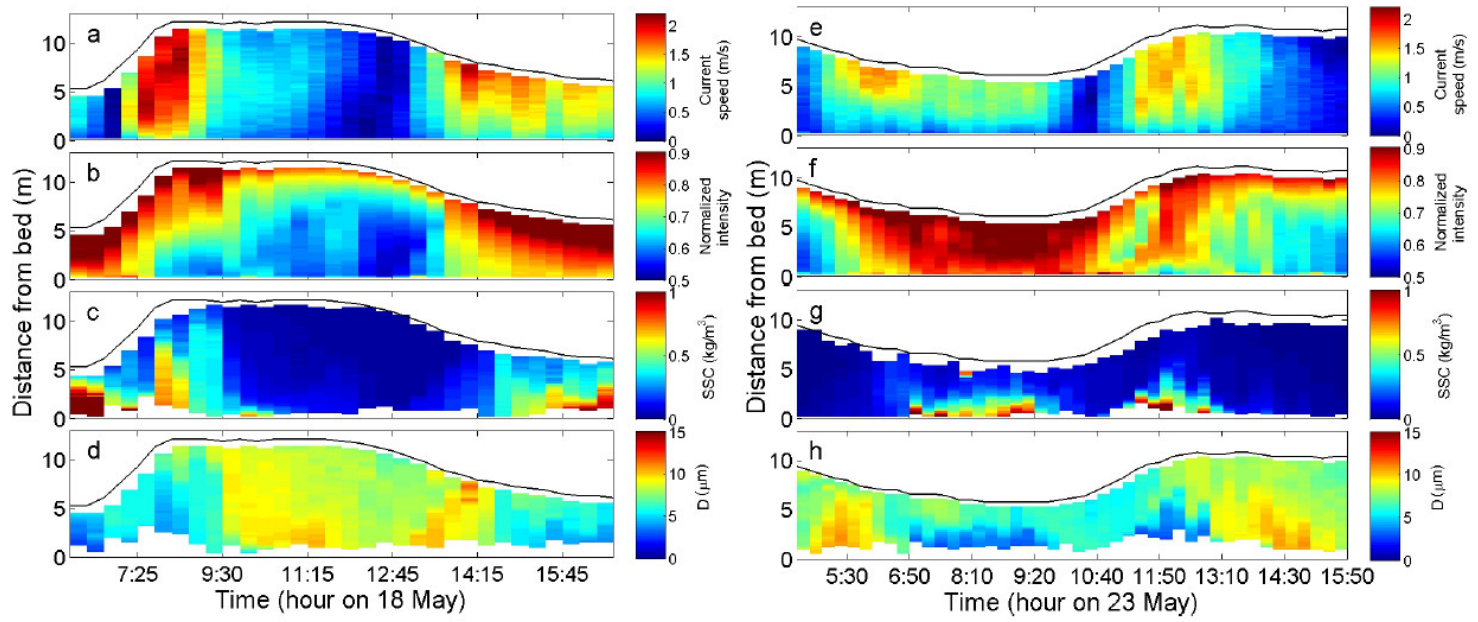

Figure 6: Observations during Spring (left panel) and Neap (right panel) tides in May 2011. Vertical structure of $(\mathrm{a}, \mathrm{e})$ mean current recorded by the ADCP, $(\mathrm{b}, \mathrm{f})$ normalized ADCP acoustic backscatter intensity, $(\mathrm{c}, \mathrm{g})$ suspended sediment concentration measured by the OBS, $(\mathrm{d}, \mathrm{h})$ mean floc size over the particle number size distribution measured by the LISST.
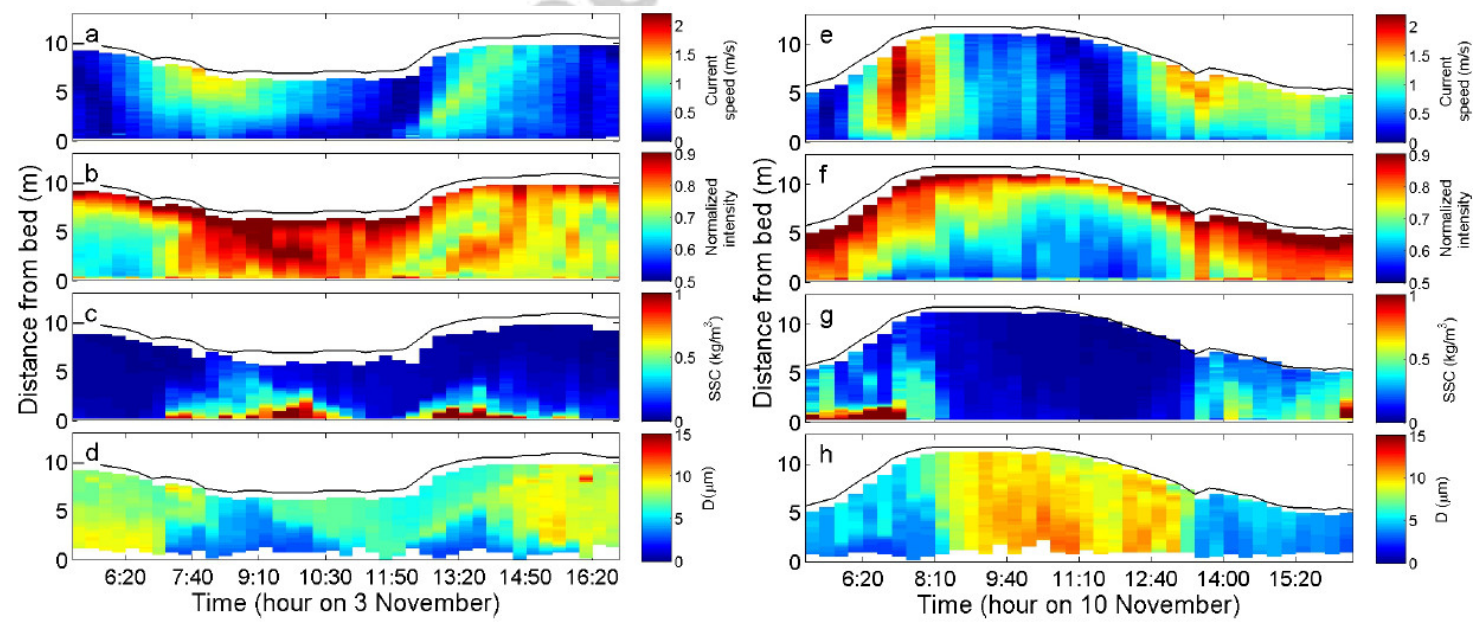

Figure 7: Observations during Neap (left panel) and Spring (right panel) tides in November 2011. Vertical structure of $(\mathrm{a}, \mathrm{e})$ mean current recorded by the ADCP, (b,f) normalized ADCP acoustic backscatter intensity, $(\mathrm{c}, \mathrm{g})$ suspended sediment concentration measured by the OBS, $(\mathrm{d}, \mathrm{h})$ mean floc size over the particle number size distribution measured by the LISST. 

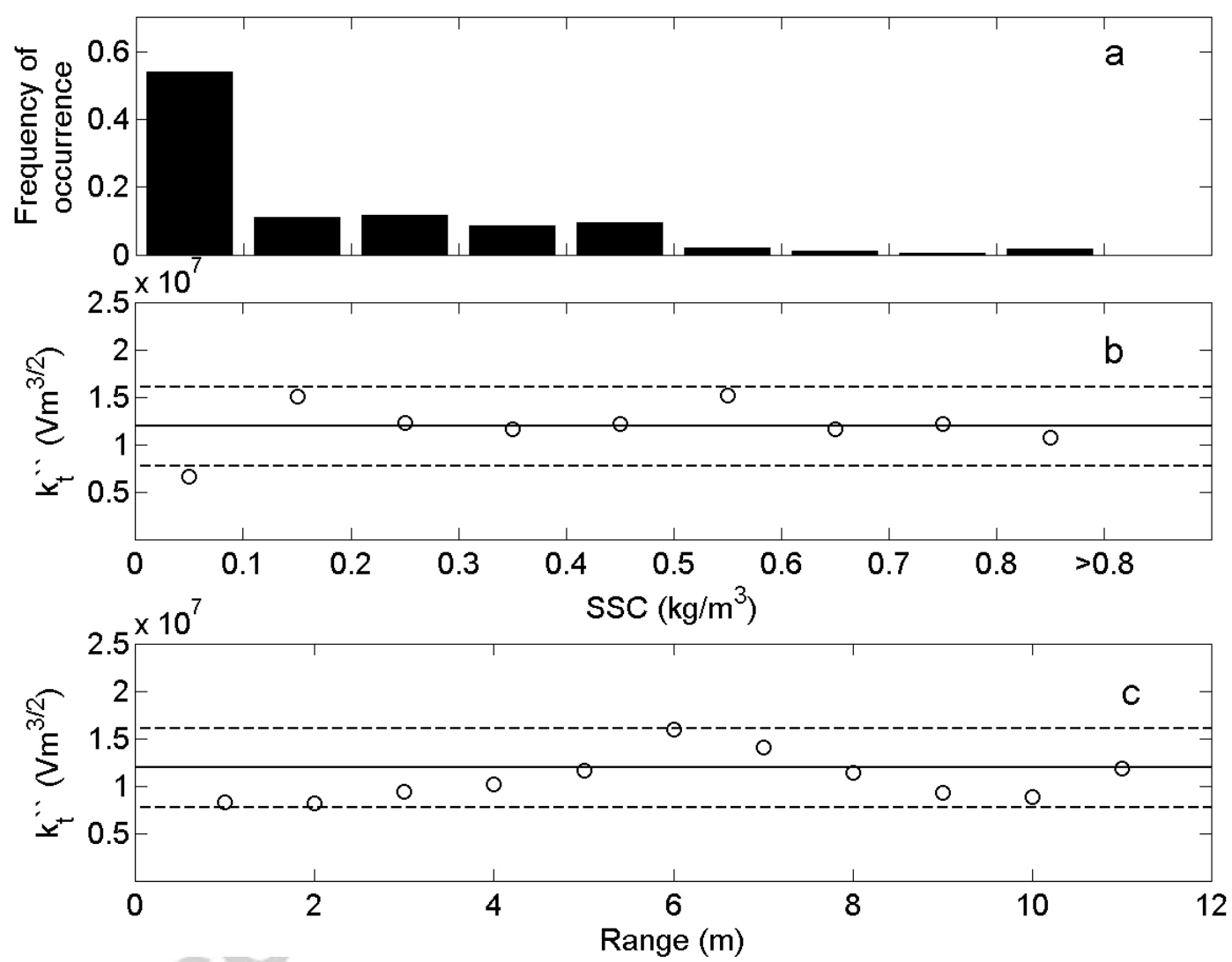

Figure 8: (a) The histogram of suspended sediment concentration observations. (b) Variation of $k_{t}$ with suspended sediment concentration. (c) Variation of $k_{t}$ with the range from the instrument. The solid line mark the averaged $k_{t}$ values over the all concentration classes, and the dashed lines are $\pm 30 \%$ difference from the average value. 

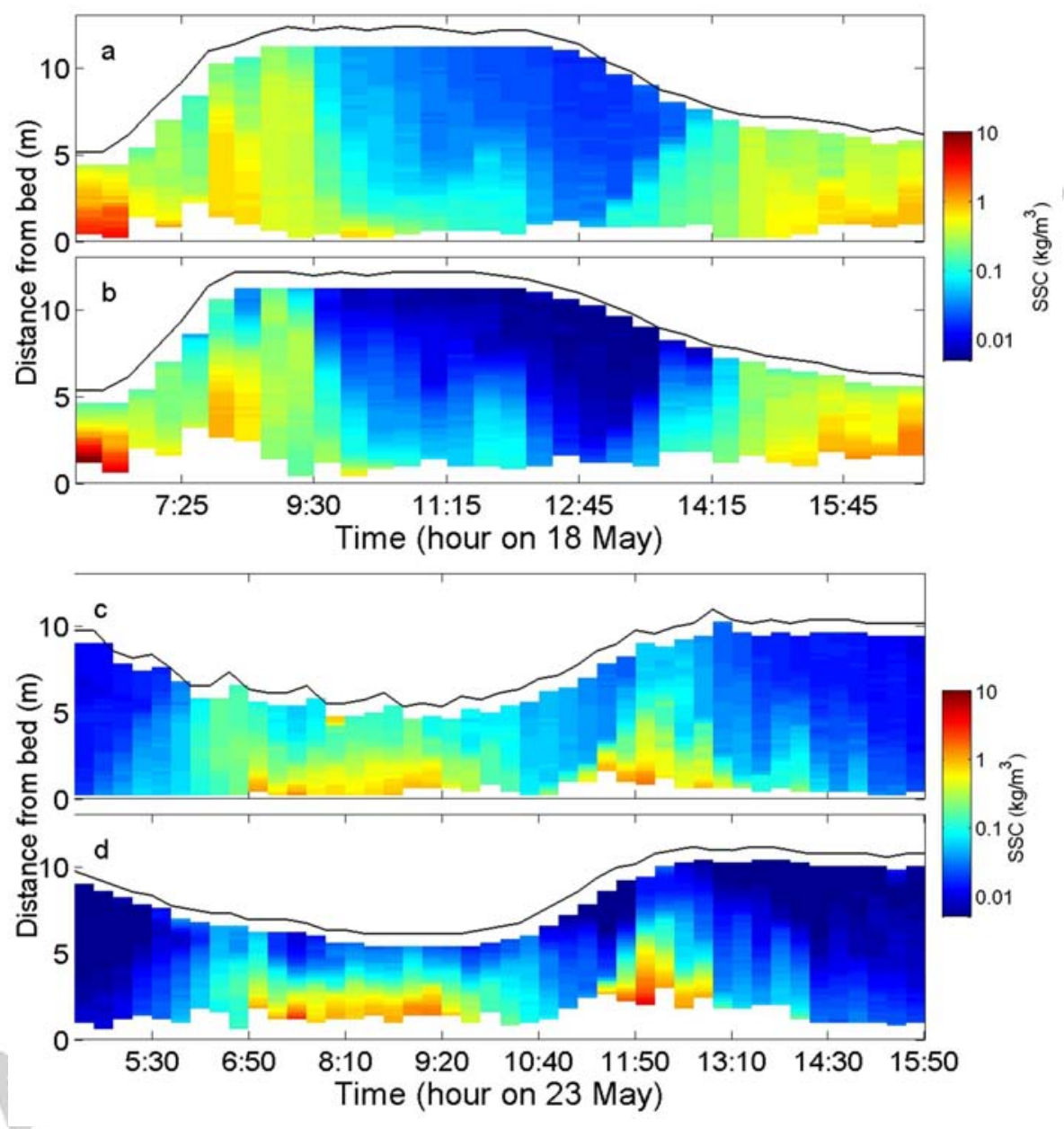

Figure 9: Evolution of SSC vertical structures $(a, c)$ measured by the OBS and (b,d) estimated from ADCP backscatter using the measured floc sizes in May 2011. The panels share the same color bar. 

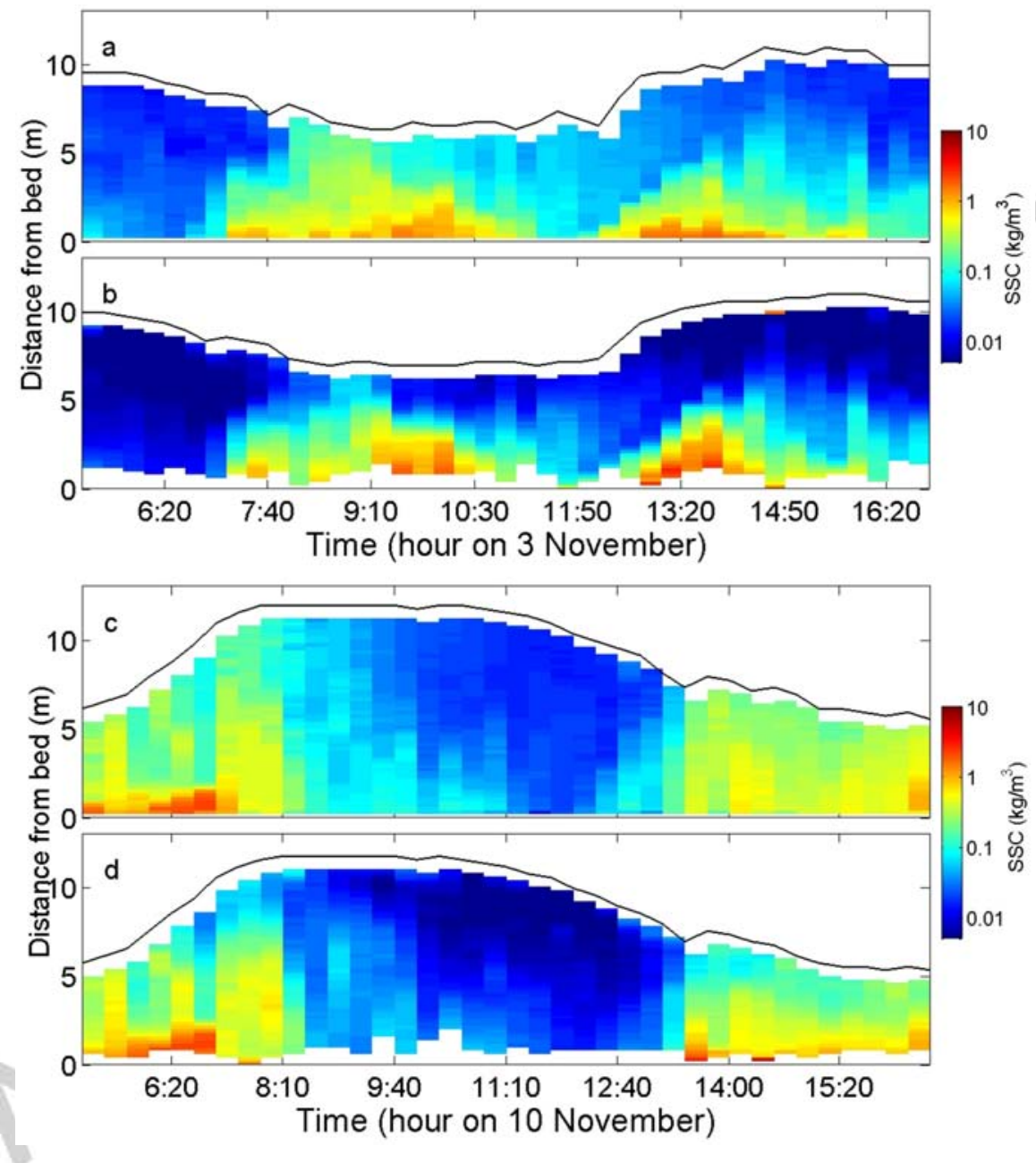

Figure 10: Evolution of SSC vertical structures (a,c) measured by the OBS and (b,d) estimated from ADCP backscatter using the measured floc sizes in November 2011. The panels share the same color bar. 

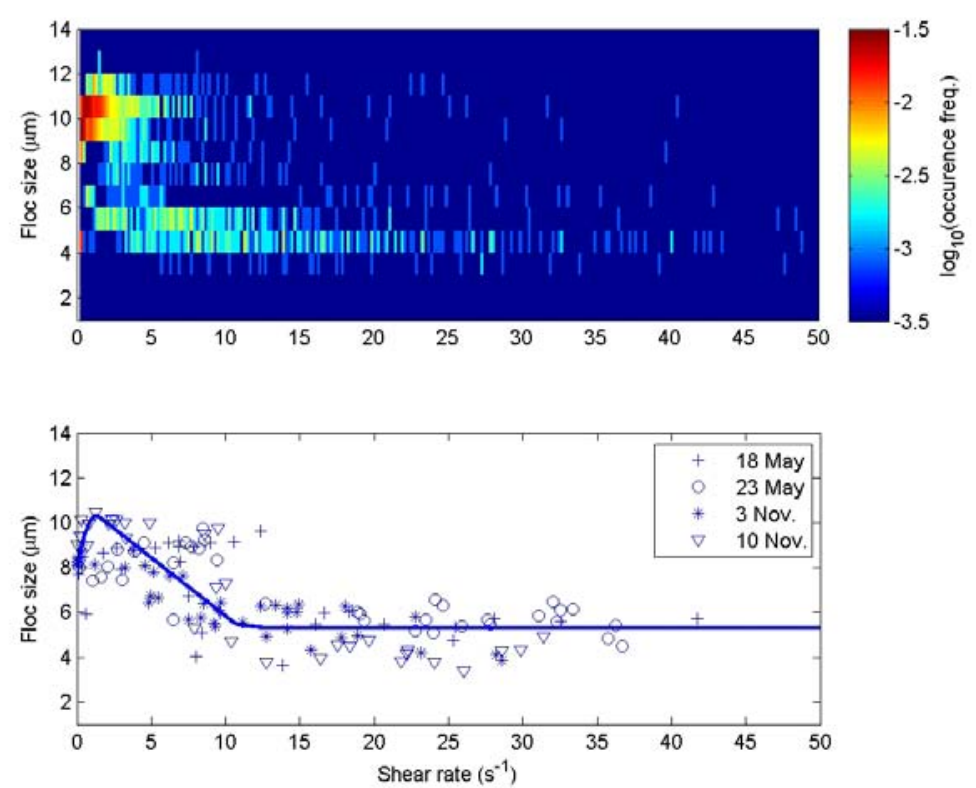

Figure 11: (a) Occurrence frequencies surface for different shear rate-floc size $\left(D_{m n}\right)$ pairs. (b) Relationship between the vertically averaged shear rates and mean floc sizes $\left(D_{m n}\right)$. Solid line represent the combination of linear regression lines for different turbulence conditions.
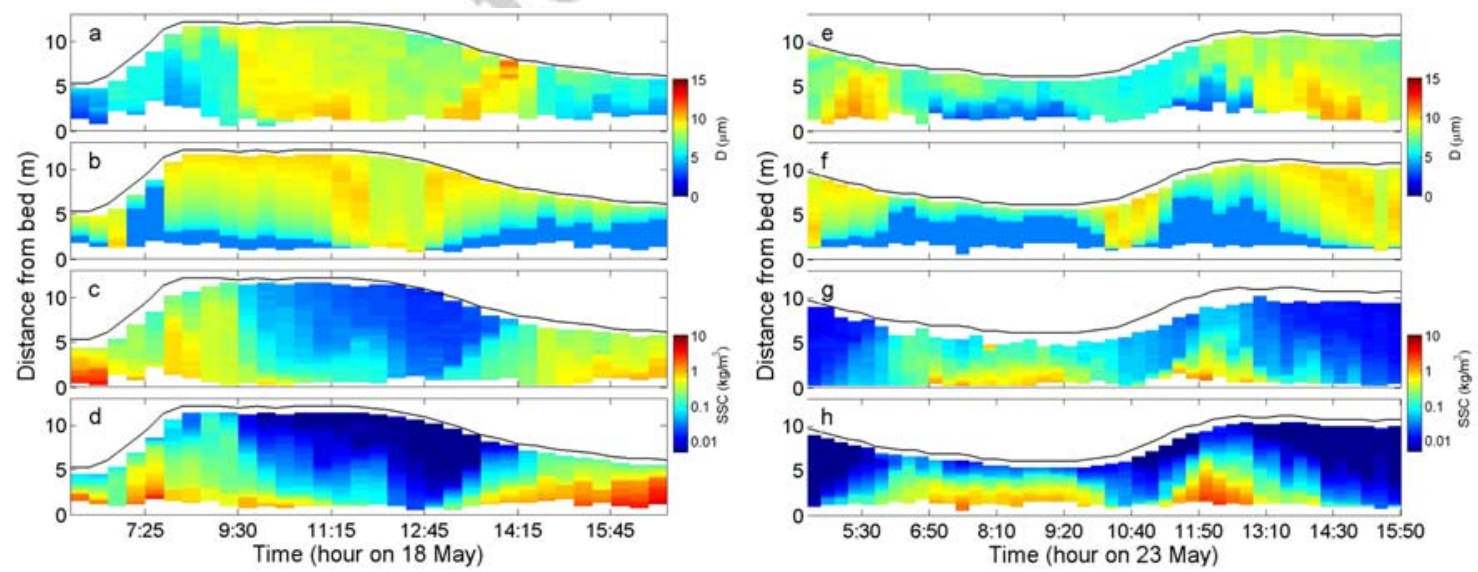

Figure 12: Comparisons during Spring (left panel) and Neap (right panel) tides in May 2011. Vertical structure of $(\mathrm{a}, \mathrm{e})$ mean floc sizes over the particle number size distributions measured by the LISST $(\mathrm{b}, \mathrm{f})$ mean floc size estimates, $(\mathrm{c}, \mathrm{g})$ suspended sediment concentration measured by the OBS, $(\mathrm{d}, \mathrm{h})$ suspended sediment concentration estimates using the estimated floc sizes. 

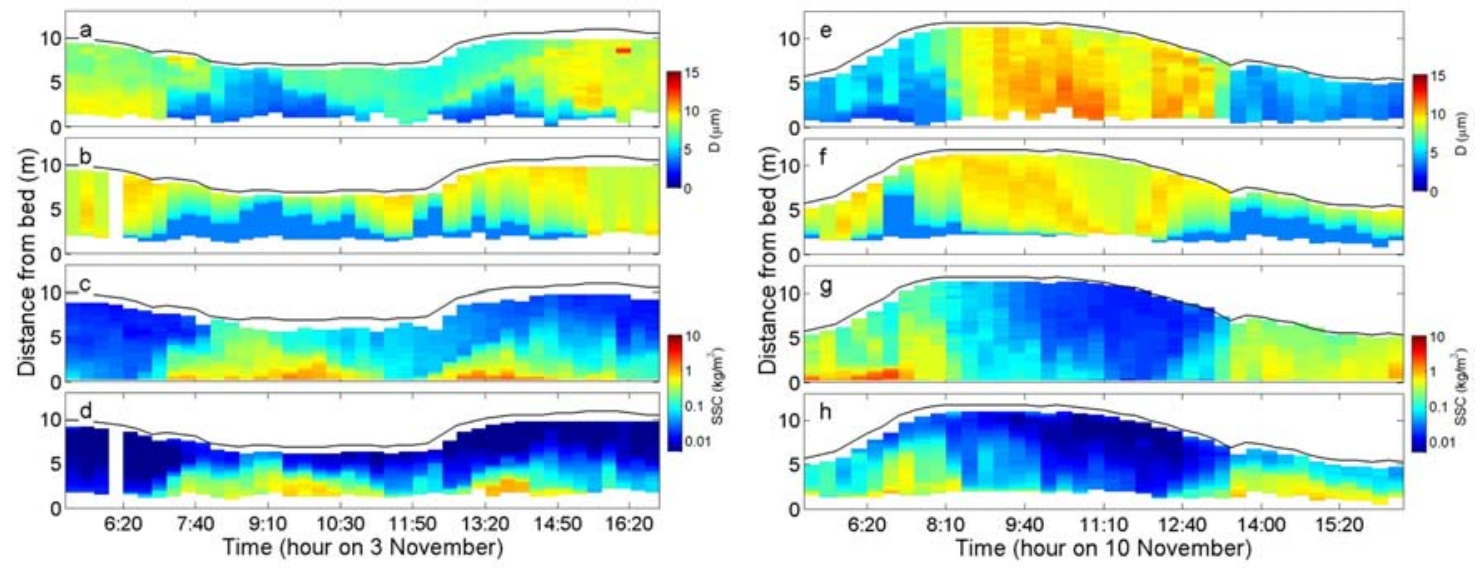

Figure 13: Comparisons during Neap (left panel) and Spring (right panel) tides in November 2011. Vertical structure of $(\mathrm{a}, \mathrm{e})$ mean floc sizes over the particle number size distributions measured by the LISST $(\mathrm{b}, \mathrm{f})$ mean floc size estimates, $(\mathrm{c}, \mathrm{g})$ suspended sediment concentration measured by the OBS, $(\mathrm{d}, \mathrm{h})$ suspended sediment concentration estimates using the estimated floc sizes.

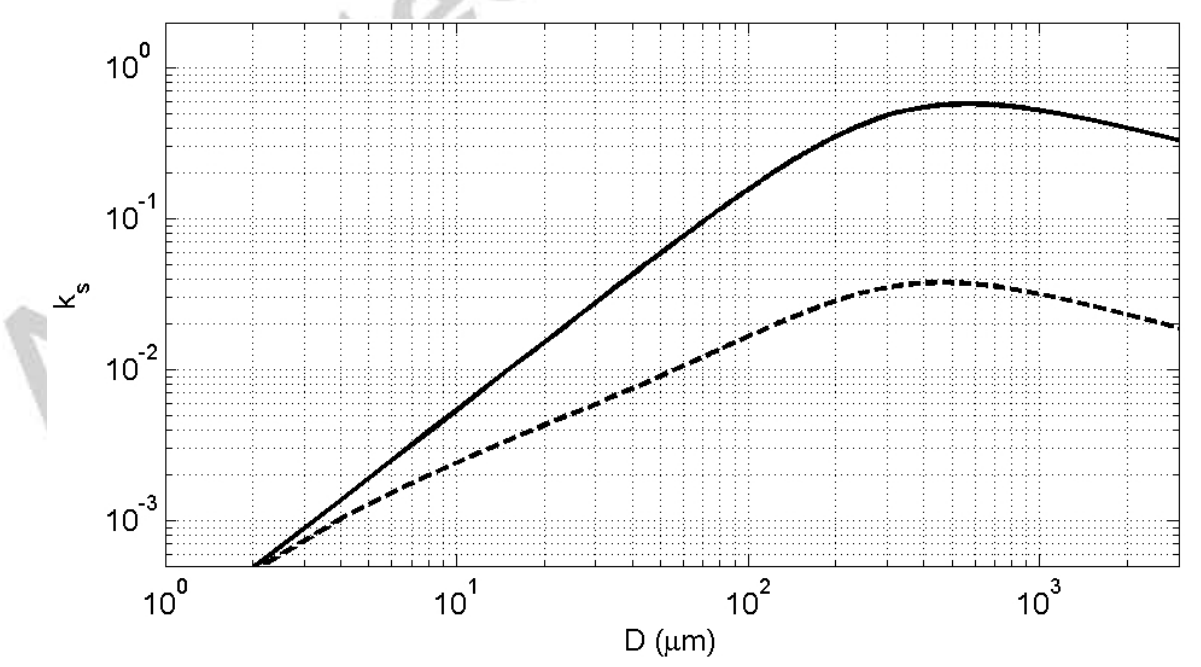

Figure 14: Variation of the sediment backscattering property, $k_{s}$, with sediment diameter (black: solid particle-scatterer model, dashed: floc-scatterer model). 


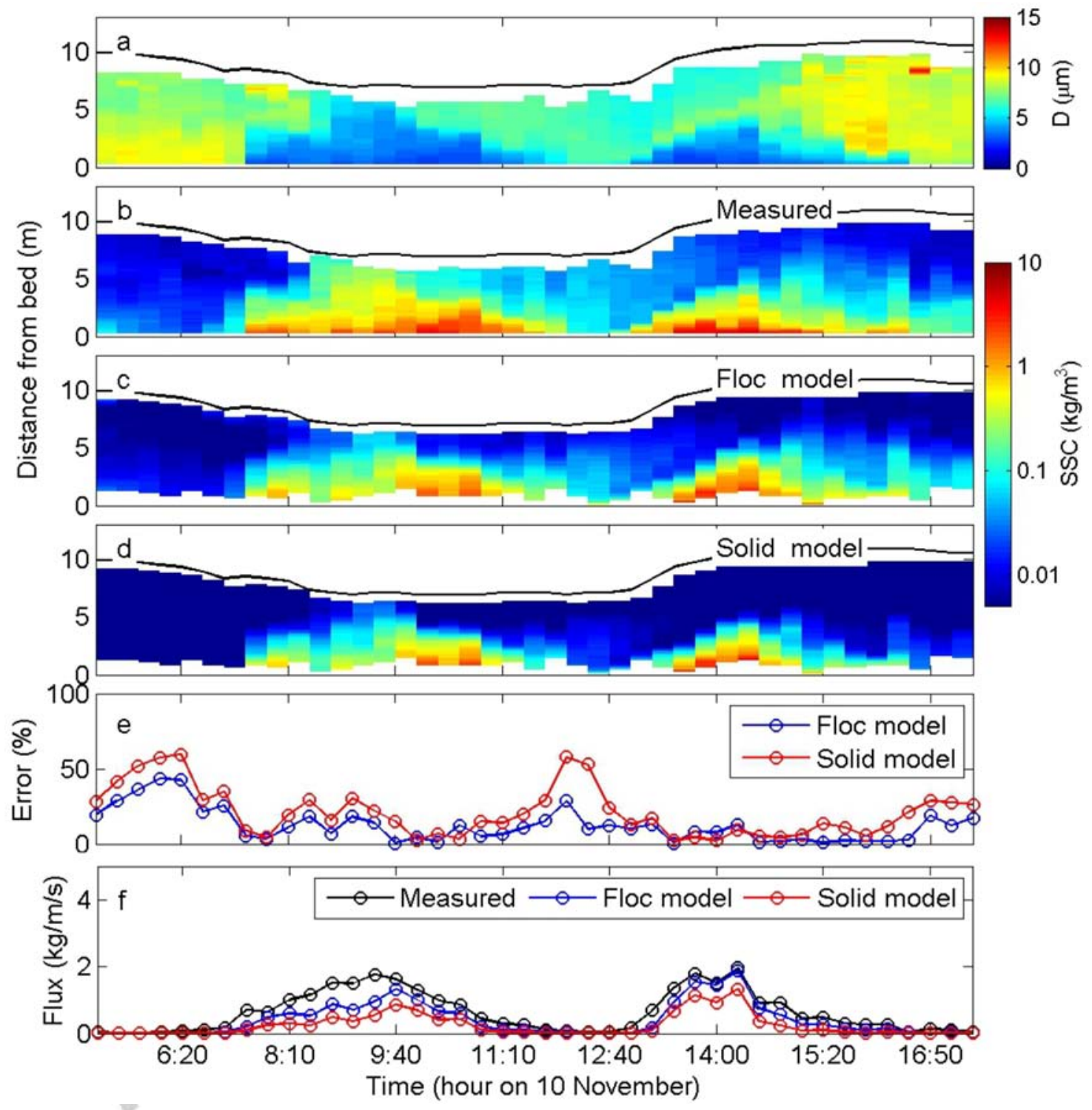

Figure 15: Comparisons during Neap tide in November 2011. Vertical structure of (a) mean floc sizes over the particle number size distributions measured by the LISST, (b) suspended sediment concentration measured by the OBS, (c) suspended sediment concentration estimates using the floc-scatterer (hybrid) model, (d) suspended sediment concentration estimates using the solid particle-scatterer model. (e) Evolution of the percentage errors for the floc-scatterer (hybrid) model and the solid particle-scatterer model. The model results are based on the measured particle sizes. 

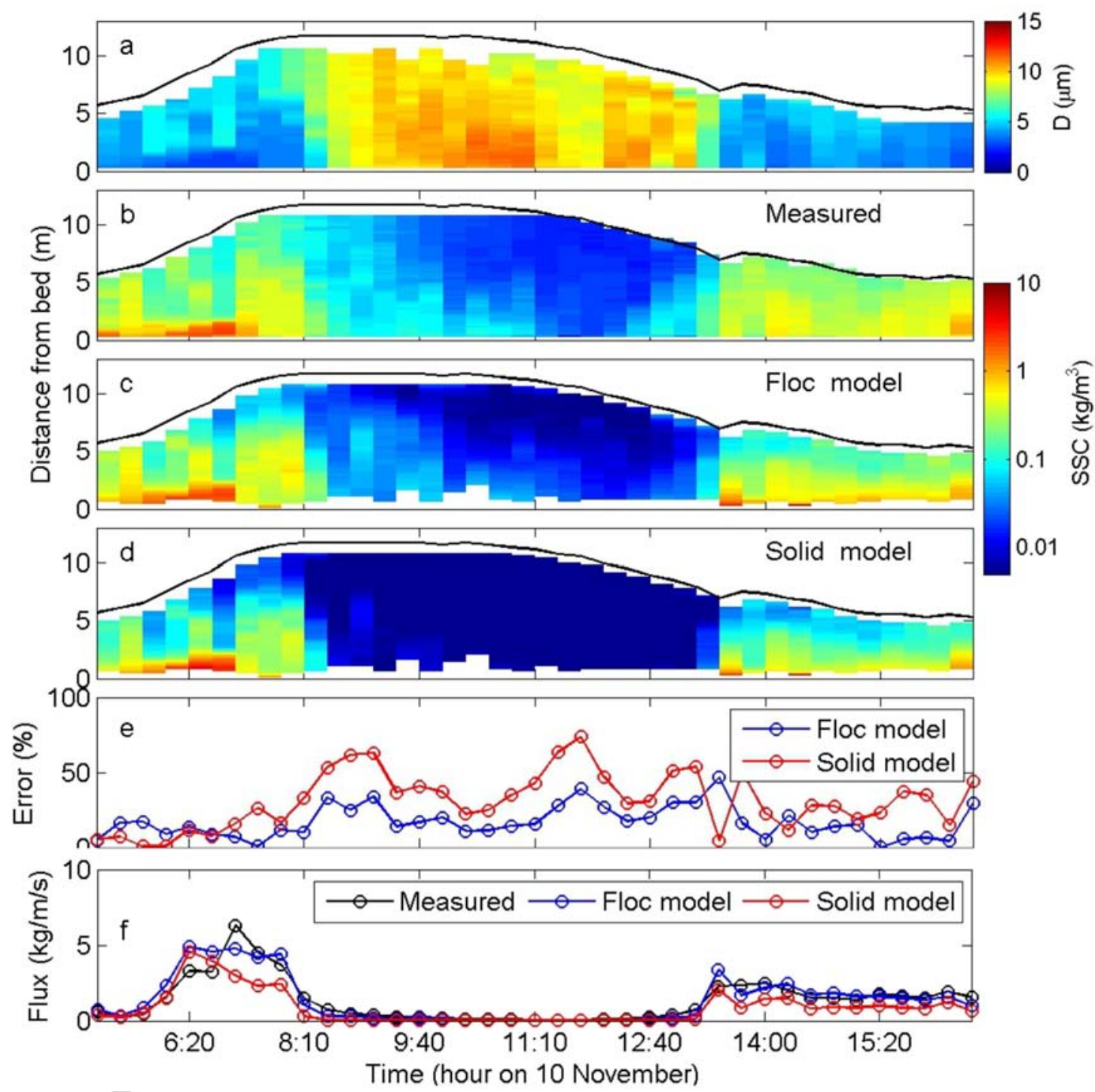

Figure 16: Comparisons during Spring tide in November 2011. Vertical structure of (a) mean floc sizes over the particle number size distributions measured by the LISST, (b) suspended sediment concentration measured by the OBS, (c) suspended sediment concentration estimates using the floc-scatterer (hybrid) model, (d) suspended sediment concentration estimates using the solid particle-scatterer model. (e) Evolution of the percentage errors for the floc-scatterer (hybrid) model and the solid particle-scatterer model. The model results are based on the measured particle sizes. 


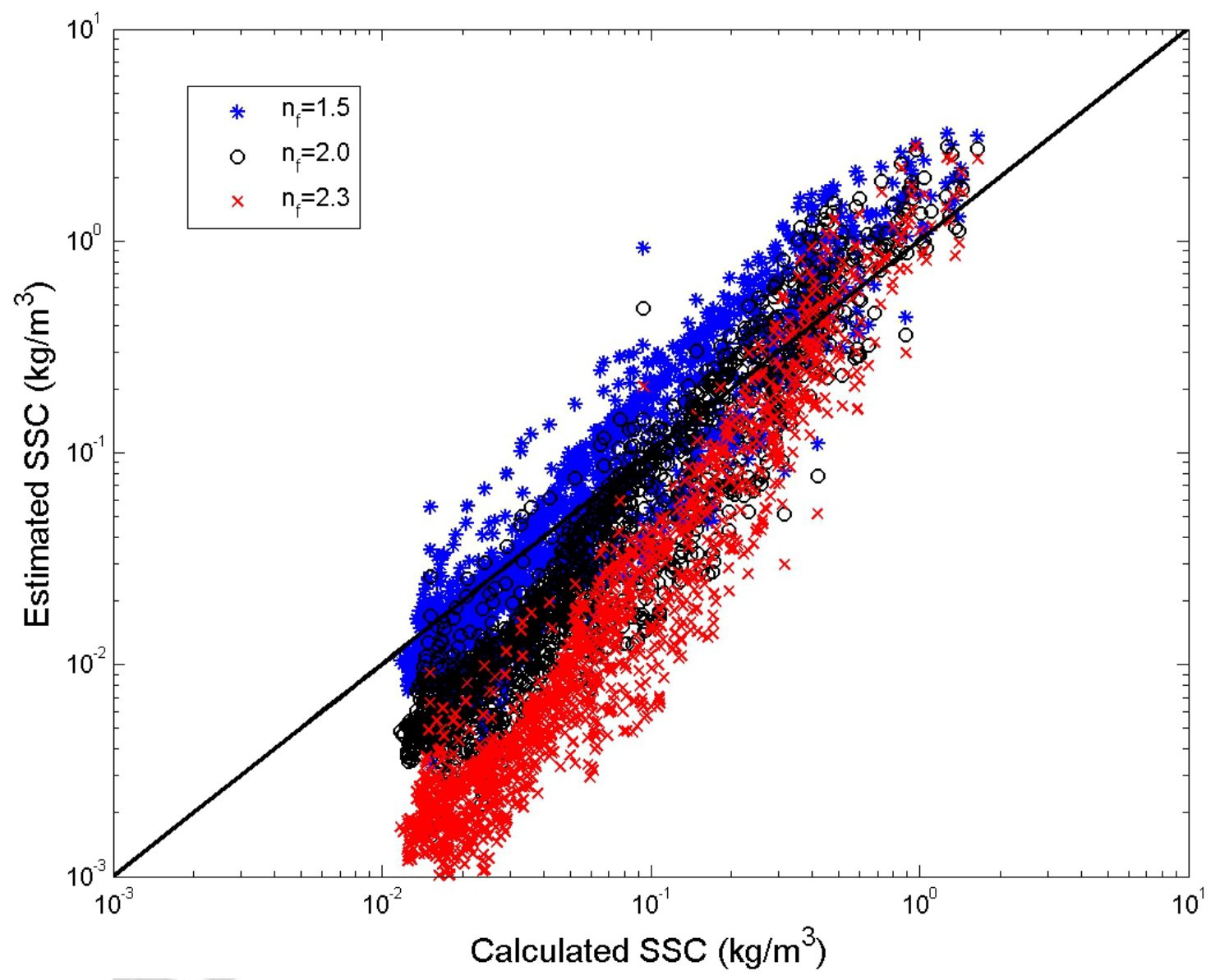

Figure 17: Correlation between measured (OBS) and estimated (ADCP) suspended sediment concentrations during Neap tide in November 2011 (red $\times$ : estimates using $n_{f}=2.3$, black $\circ$ : estimates using $n_{f}=2$, blue $*$ : estimates using $n_{f}=1.5$ ). 